\title{
Effects of endovascular and surface cooling on resuscitation in patients with cardiac arrest and a comparison of effectiveness, stability, and safety: a systematic review and meta-analysis
}

Xueli Liao ${ }^{\dagger}$, Ziyu Zhou ${ }^{\dagger}$, Manhong Zhou ${ }^{*}{ }^{\dagger}$, Hui Tang, Menglong Feng, Bujin Kou, Ni Zhu, Futuan Liao and Liaozhang Wu

\begin{abstract}
Objectives: This study conducted a meta-analysis to assess the effectiveness, stability, and safety of mild therapeutic hypothermia (TH) induced by endovascular cooling (EC) and surface cooling (SC) and its effect on ICU, survival rate, and neurological function integrity in adult CA patients.

Methods: We developed inclusion criteria, intervention protocols, results, and data collection. The results included outcomes during target temperature management as well as ICU stay, survival rate, and neurological functional integrity. The characteristics of the included population and each study were analyzed.

Results: Four thousand nine hundred thirteen participants met the inclusion criteria. Those receiving EC had a better cooling efficiency (cooling rates $\mathrm{MD}=0.31[0.13,0.50], p<0.01$; induced cooling times $\mathrm{MD}=-90.45[-$ 167.57, -13.33$], p=0.02$; patients achieving the target temperature $R R=1.60[1.19,2.15], p<0.01)$ and thermal stability during the maintenance phase (maintenance time $\mathrm{MD}=2.35[1.22,3.48], p<0.01$; temperature fluctuation $\mathrm{MD}=-0.68[-1.03,-0.33], p<0.01$; overcooling $\mathrm{RR}=0.33[0.23,0.49], p<0.01)$. There were no differences in ICU survival rate $\left(\mathrm{RR}=1.22[0.98,1.52], p=0.07, P^{2}=0 \%\right)$ and hospital survival rate $(\mathrm{RR}=1.02[0.96$, 1.09], $\left.p=0.46, P^{2}=0 \%\right)$, but $\mathrm{EC}$ reduced the length of stay in ICU $\left(\mathrm{MD}=-1.83[-3.45,-0.21], p=0.03, P^{2}=49 \%\right)$ and improved outcome of favorable neurological function at discharge $\left(R R=1.15[1.04,1.28], p<0.01, P^{2}=0 \%\right)$. EC may delay the hypothermia initiation time, and there was no significant difference between the two cooling methods in the time from the start of patients' cardiac arrest to achieve the target temperature $(M D=-46.64[-175.86,82.58])$. EC was superior to non-ArcticSun in terms of cooling efficiency. Although there was no statistical difference in ICU survival rate, ICU length of stay, and hospitalization survival rate, in comparison to non-ArcticSun, EC improved rates of neurologically intact survival $(\mathrm{RR}=1.16[1.01,1.35], p=$ $0.04, P^{2}=0 \%$.

\footnotetext{
* Correspondence: manahongzhou@126.com

${ }^{+}$Xueli Liao, Ziyu Zhou, and Manhong Zhou are joint first authors. These authors contributed equally to the work.

The Emergency Department, The Affiliated Hospital of Zunyi Medical

University, Zunyi 563003, China
}

(c) The Author(s). 2020 Open Access This article is distributed under the terms of the Creative Commons Attribution 4.0 International License (http://creativecommons.org/licenses/by/4.0/), which permits unrestricted use, distribution, and reproduction in any medium, provided you give appropriate credit to the original author(s) and the source, provide a link to the Creative Commons license, and indicate if changes were made. The Creative Commons Public Domain Dedication waiver (http://creativecommons.org/publicdomain/zero/1.0/) applies to the data made available in this article, unless otherwise stated. 
(Continued from previous page)

Conclusions: Among adult patients receiving cardiopulmonary resuscitation, although there is no significant difference between the two cooling methods in the time from the start of cardiac arrest to achieve the target temperature, the faster cooling rate and more stable cooling process in EC shorten patients' ICU hospitalization time and help more patients obtain good neurological prognosis compared with patients receiving SC. Meanwhile, although EC has no significant difference in patient outcomes compared with ArcticSun, EC has improved rates of neurologically intact survival.

Keywords: Cardiac arrest, Mild therapeutic hypothermia, Target temperature management, Endovascular cooling, Surface cooling, Systematic review

\section{Background}

Patients with disordered consciousness who are admitted to the intensive care unit (ICU) for further treatment after out-of-hospital cardiac arrest (OHCA) resuscitation still have an undefined prognosis, high risk of death, and severe damage to nervous system function [1]. Nerve damage is the most common cause of death in OHCA patients [2]. Andreja et al. analyzed factors such as age, initial rhythms, resuscitation process, drug use, and recovery of nervous system function in patients with cardiac arrest (CA) and found that nerve damage was the most significant independent predictor of mortality within 6 months after cardiopulmonary resuscitation (CPR) in hospitalized OHCA patients. Early induction of mild therapeutic hypothermia $(\mathrm{TH})$ is an effective method of reducing central nervous system function damage after CPR in CA patients [3].

Although nearly 60 years ago $\mathrm{TH}$ was considered to be beneficial to CA survivors [4-6], the technology did not become popular and widely used in clinical practice until after Bernard et al. and the Hypothermia after Cardiac Arrest Study Group (HACA) reported the benefits of hypothermia after cardiac arrest [7, 8]. Subsequently, relevant studies have shown that the induction of mild hypothermia after admission can improve the neurological function prognosis and improve the survival rate of the patients [8, 9]. The 2015 European Resuscitation Council Guidelines for Resuscitation state that $\mathrm{TH}$ may benefit OHCA patients with initial shockable rhythms after the return of spontaneous circulation (ROSC) [10]. The American Heart Association (AHA), the European Resuscitation Council (ERC), and the International Liaison Committee on Resuscitation (ILCOR) have provided postrecovery guidelines that recommend using $\mathrm{TH}$ or targeted temperature management (TTM) for follow-up treatment of eligible patients after CA resuscitation [11-13]. A related metaanalysis reviewed 1974 articles, including 6 randomized controlled trials (RCTs) and 8 observational studies, and showed low-quality evidence supporting the finding that OHCA survivors with initial shockable rhythms can improve their survival rate and neurological functional prognosis after hypothermia is induced and maintained for $18-24 \mathrm{~h}$ at $32-36^{\circ} \mathrm{C}$ after being admitted to hospital [14].

After defining the $\mathrm{TH}$ plan and process after CA resuscitation, issues such as the cooling method, safety, cooling efficiency, related complications, and survival outcomes of the patients need to be considered. The current cooling equipment can be classified into three categories: $[15,16]$ (1) traditional cooling technology; (2) surface cooling systems; and (3) endovascular cooling systems. Traditional techniques include intravenous infusion of cooled saline, nasal evaporation, hollow organ cooling, ice packs, ice caps, ice blankets, and cold air blankets; surface cooling systems utilize electric conduction via adherent gel pads to create cold fluid flow, which results in accurate temperature feedback control; the endovascular cooling system consists of a heat exchange catheter placed in a large central vein through which temperature-controlled saline is circulated to indirectly cool the blood instead of directly injecting saline into the bloodstream, thereby achieving precise control of the blood temperature [15]. Compared with the above various cooling methods, endovascular catheter cooling seems to be more accurate and reliable than other cooling methods in terms of cooling efficiency and maintaining the target temperature [17-19]. Due to the lack of a direct comparison of clinical outcome data, it is not known whether another TH method is significantly better. In the past, it was thought that faster cooling and greater stability of the target temperature may improve the survival rate and the integrity of nervous system function, but further clinical research evidence is needed [20]. Which method is better? In particular, are surface cooling systems or endovascular cooling systems better? As there is limited data providing a direct comparison of clinical outcomes, no definitive conclusions can be reached, and further research is needed.

At present, there are various methods of cooling, and the best cooling method has yet to be determined. The available methods should be carried out in three stages: 
the induced cooling phase, maintenance phase, and rewarming phase. Therefore, this study included all available raw data from relevant studies to systematically compare the treatment effectiveness, stability, safety, survival rate, and neurological function in CA patients receiving EC and SC during the three stages, namely, induction, maintenance, and rewarming.

\section{Methods}

This meta-analysis was conducted according to the Preferred Reporting Items for Systematic Reviews and Meta-Analysis (PRISMA) statement [21].

\section{Review questions}

The review questions were based on the PICO protocol (population, intervention, comparison, outcomes). What are the differences between endovascular cooling therapy (I) and surface cooling therapy (C) in terms of the length of stay in the ICU, survival rate, and favorable neurological outcome at discharge $(\mathrm{O})$ in admitted adults following successful resuscitation after CA (P)? Are there any differences in cooling performance and stability between EC and SC?

\section{Inclusion and exclusion criteria}

Inclusion criteria: (1) all studies were full-text articles published in index journals and included in-hospital cardiac arrest (IHCA) or out-of-hospital cardiac arrest (OHCA) adult patients (age $\geq 18$ years) who remained comatose after CPR; (2) all studies compared EC and $\mathrm{SC}$ after CA, and the body temperature should not be lower than $34^{\circ} \mathrm{C}$ before the induction of cooling; (3) all studies included patients with CA caused by cardiac or non-cardiac factors (except brain injury) and arrhythmia including ventricular fibrillation (VF), ventricular tachycardia (VT), pulseless electrical activity (PEA), and asystole; and (4) the results include cooling efficiency, body temperature maintenance stability, rewarming efficiency, the length of stay in the ICU, ICU survival rate, hospital survival rate, and favorable neurological function at discharge.

\section{Exclusion criteria}

CA caused by trauma; patients with coagulopathy, endstage disease, severe bleeding, or pregnancy; and reviews, case reports, and abstracts. There are no restrictions on language or publication years.

\section{Database search}

The PubMed, EMBASE (OVID), and Cochrane databases (from inception to March 2019) were searched without language restrictions. The keywords were as follows: heart arrest, cardiac arrest, cardiopulmonary arrest, hypothermia, induced hypothermia, therapeutic hypothermia, targeted temperature management, temperature management, invasive cooling, intravascular cooling, endovascular cooling, intravenous infusion, surface cooling, traditional, and conventional. In addition, we examined the bibliographies of relevant research and review articles.

\section{Study selection}

We imported all retrieved results into EndNote and eliminated any duplicates. Two authors independently evaluated the retrieved titles and abstracts to determine their compliance with the full-text review criteria. For all documents that were not excluded at this stage, we read the full-text articles and determined if they met the inclusion criteria. In the end, any different opinions between the evaluators were resolved by consensus or the third reviewer.

\section{Data extraction}

We extracted the following data: the basic characteristics of the included population (Table 1), such as ethnicity, number of patients, location of CA (IHCA/OHCA), cause of CA, sex and age of patients, and initial rhythm, and the study characteristics (Table 2), such as research type, cooling method, temperature measurement, and outcomes. We then entered the data into the Cochrane Software Program Review Manager [42] to obtain the final statistical results.

\section{Study outcome definition}

\section{Evaluation of cooling methods}

Effectiveness was measured by the (1) induced cooling times (from the start of cooling to the time at which the target temperature was obtained $\left(<34.0^{\circ} \mathrm{C}\right)$, expressed in $\mathrm{min}$ ), (2) cooling rates (from the beginning of cooling to the first body temperature $<$ $34.0^{\circ} \mathrm{C}$, expressed as ${ }^{\circ} \mathrm{C} / \mathrm{h}$ ), and (3) patients achieving the target body temperature. Stability was measured by the (4) temperature fluctuations during maintenance $\left({ }^{\circ} \mathrm{C}\right),(5)$ average target temperature $\left({ }^{\circ} \mathrm{C}\right)$ and target temperature maintenance time (h) (i.e., body temperature maintained at $32-34{ }^{\circ} \mathrm{C}$ ), and (6) overcooling (at least one body temperature $<32.0^{\circ} \mathrm{C}$ during body temperature maintenance). The rewarming stage was measured by the (7) rewarming times (h) and speed $\left({ }^{\circ} \mathrm{C} / \mathrm{h}\right)$ (i.e., temperature increases to > $37.0^{\circ} \mathrm{C}$ ), and (8) rebound hyperthermia (i.e., the body temperature reaches or exceeds $38^{\circ} \mathrm{C}$ ). The core temperature was mainly measured in the throat, esophagus, urinary tract, rectum, or veins.

\section{Definition of survival and outcomes}

The primary outcome was favorable neurological function at discharge, in which favorable neurological 


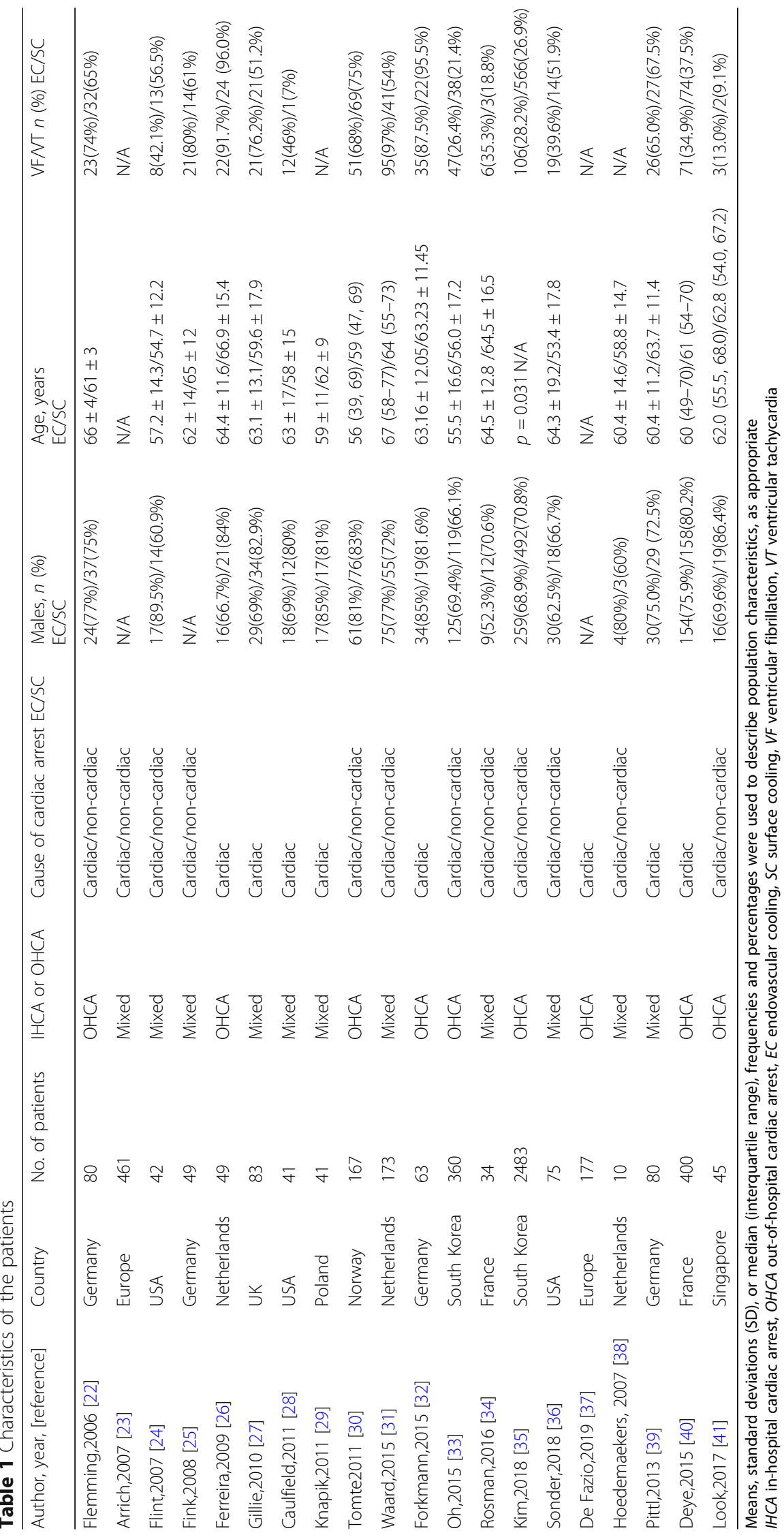




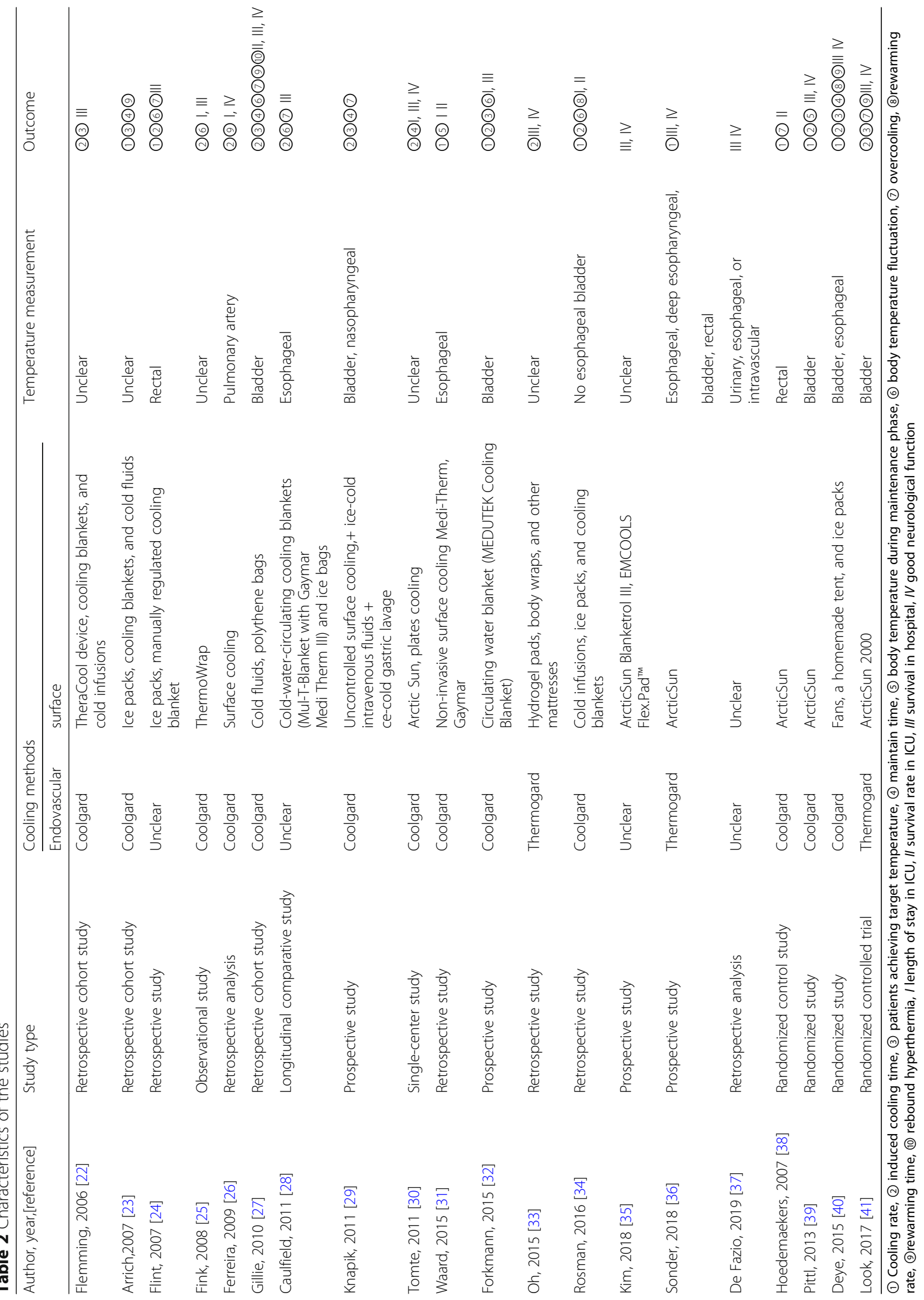


function was defined as returning home after discharge or being sent to a rehabilitation facility and a Cerebral Performance Categories Scale (CPC) score of 1 or 2 points $[43,44]$. The secondary outcomes included the length of stay in the ICU, ICU survival rate, and hospital survival rate.

\section{Results}

\section{Study selection}

In total, 3018 articles were retrieved from the PubMed, EMBASE (OVID), and Cochrane databases; of those, 398 duplicated articles were removed, 91 articles were reviewed, and 71 articles did not meet the inclusion criteria. Finally, 20 articles were included in the systematic review, as shown in Fig. 1.

\section{Characterization of studies and patients}

Twenty studies were eventually included. There were 16 cohort studies [22-37] and 4 RCTs [38-41]. The analysis included 14 single-center studies and 6 multicenter studies [23, 31, 33, 35-37]. Eleven studies included IHCA patients and OHCA patients, and 9 studies only included OHCA patients. From these studies, we extracted data on the causes of CA, including 10 studies with patients with CA caused by cardiac factors and 10 studies with patients with $\mathrm{CA}$ caused by cardiac or non-cardiac factors. The initial rhythms at the time of CA included shockable rhythms (e.g., VF or VT) and non-shockable rhythms (e.g., asystole or PEA), which were not clearly designated in the studies.

\section{Selection of TH methods}

All were the contrast between EC and SC; however, the selection of equipment differed among the studies. In terms of EC, 16 studies used the Coolgard/Thermogard system [15] to compare with surface cooling, and the remaining 4 studies $[24,28,35,37]$ did not indicate specific endovascular cooling equipment used. In terms of SC, 6 studies [30, 35, 36, 38, 39, 41] selected ArcticSun equipment [45] for surface cooling, and other studies included ice packs, cooling blankets, cold liquid infusions, and intracavity perfusion cooling. The core temperature measurements of the 14 studies were performed in the pharynx, esophagus, bladder, rectum, and pulmonary arteries. The remaining six studies [22, 23, 25, 30, 33, 35] did not specify where the temperature measurements were taken (Table 2). In addition, the basic characteristics of the populations included in each study were compared (Table 3).

\section{Data synthesis and analysis}

We performed a meta-analysis on the results of the included studies using Review Manager 5.3,22, and the

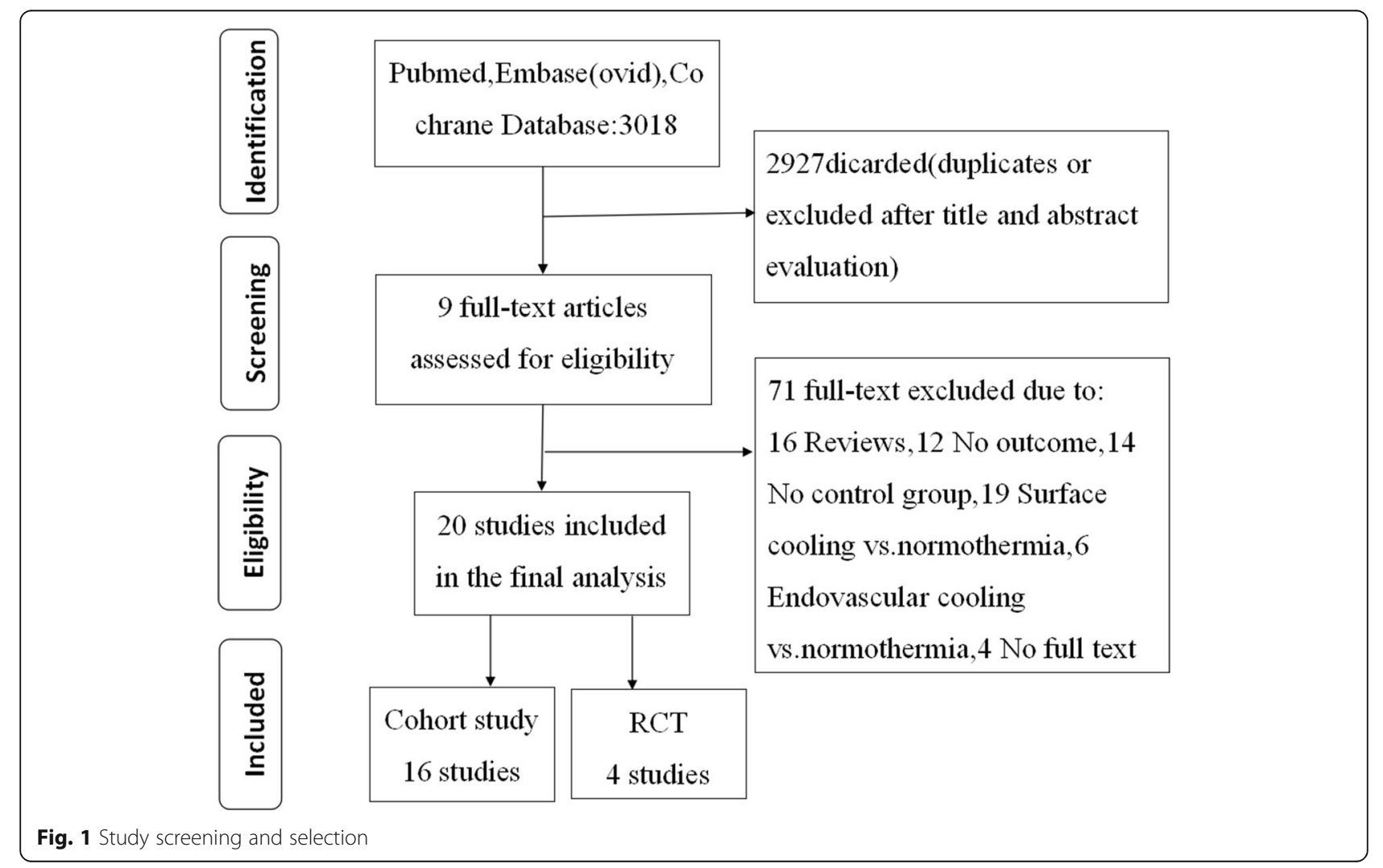


Table 3 Baseline comparison of the patients

\begin{tabular}{ll}
\hline Baseline & Effect \\
\hline Gender & $\mathrm{RR}=0.98[0.94,1.02], p=0.28$ \\
Age & $\mathrm{MD}=0.80[-1.35,2.94], p=0.47$ \\
AF/AT & $\mathrm{RR}=1.07[0.93,1.22], p=0.35$ \\
Witness & $\mathrm{RR}=1.06[0.23,1.23], p=0.41$ \\
ROSC & $\mathrm{MD}=-1.26[-3.68,1.15], p=0.31$ \\
CAG & $\mathrm{RR}=1.15[0.84,1.56], p=0.38$ \\
$\mathrm{PCl}$ & $\mathrm{RR}=0.94[0.72,1.22], p=0.63$ \\
\hline
\end{tabular}

$V F$ ventricular fibrillation, $V T$ ventricular tachycardia, $R O S C$ return of spontaneous circulation, $C A G$ coronary angiography, $P C l$ percutaneous coronary intervention

results were compared using a random effects model. With regard to the dichotomous data, the categorical data are summarized according to the MantelHaenszel method and risk ratios (RRs). With regard to the continuous data, we used the inverse variance method and the mean difference (MD), expressed as the mean \pm standard deviation; according to the method described by Wan, the average values and standard deviations from individual studies were estimated from the medians and quartile ranges as needed [46]. The results are represented by forest plots. The heterogeneity of the pooled data was estimated by calculating the $Q$ and $I^{2}$ statistics, and the difference was considered significant when $p<0.05$ or $I^{2} \geq 50 \%$ [47]. For the results with high heterogeneity, sensitivity analysis was performed through the subgroup analysis and method of excluding single studies that may have greater heterogeneity.

\section{Outcomes}

The 20 studies included 4913 patients with successful resuscitation after $\mathrm{CA}$. After statistically analyzing the characteristics of patients that may affect the outcome, we found that there was no difference between the two groups in the basic characteristics of the individuals, such as sex, age, and initial rhythm. Additionally, there was no difference between the two groups in other variables such as witnesses, ROSC time, coronary angiography (CAG), or percutaneous coronary intervention (PCI). Therefore, we believe that the two groups of patients are comparable (Table 3). At the same time, we performed an initial temperature comparison with 7 studies $[26,30,31,33,34,40,41]$ comparing the initial body temperatures of the patient before $\mathrm{TH}$ initiation and found no difference in body temperatures between the two groups before cooling $(\mathrm{MD}=-0.11[-0.34$, 0.12 ], $p=0.37, I^{2}=60 \%$ ); other studies with unclear initial body temperatures also indicated that there was no significant difference between the two groups in initial body temperature at the time of admission or before the start of $\mathrm{TH}$.

Eighteen studies referred to the index of cooling efficiency and were divided into cohort study group and RCT group according to the type of study. The cooling rates (cohort study group: $\mathrm{MD}=0.39[0.04,0.74], I^{2}=$ 94\%; RCT group: $\mathrm{MD}=0.17$ [0.02, 0.32], $I^{2}=91 \%$ ), induced cooling time (cohort study group: $\mathrm{MD}=-93.83$ $[-187.37,-0.29], \mathrm{I}^{2}=99 \% ; \mathrm{RCT}$ group: $\mathrm{MD}=-78.39$ [-180.62, 23.83], $I^{2}=89 \%$ ), and the number of patients achieving the target temperature (cohort study group: $\mathrm{RR}=2.31$ [1.21, 4.41], $I^{2}=96 \%$; RCT group: $\mathrm{RR}=1.75$ $\left.[0.43,7.09], I^{2}=84 \%\right)$. The results showed that EC was

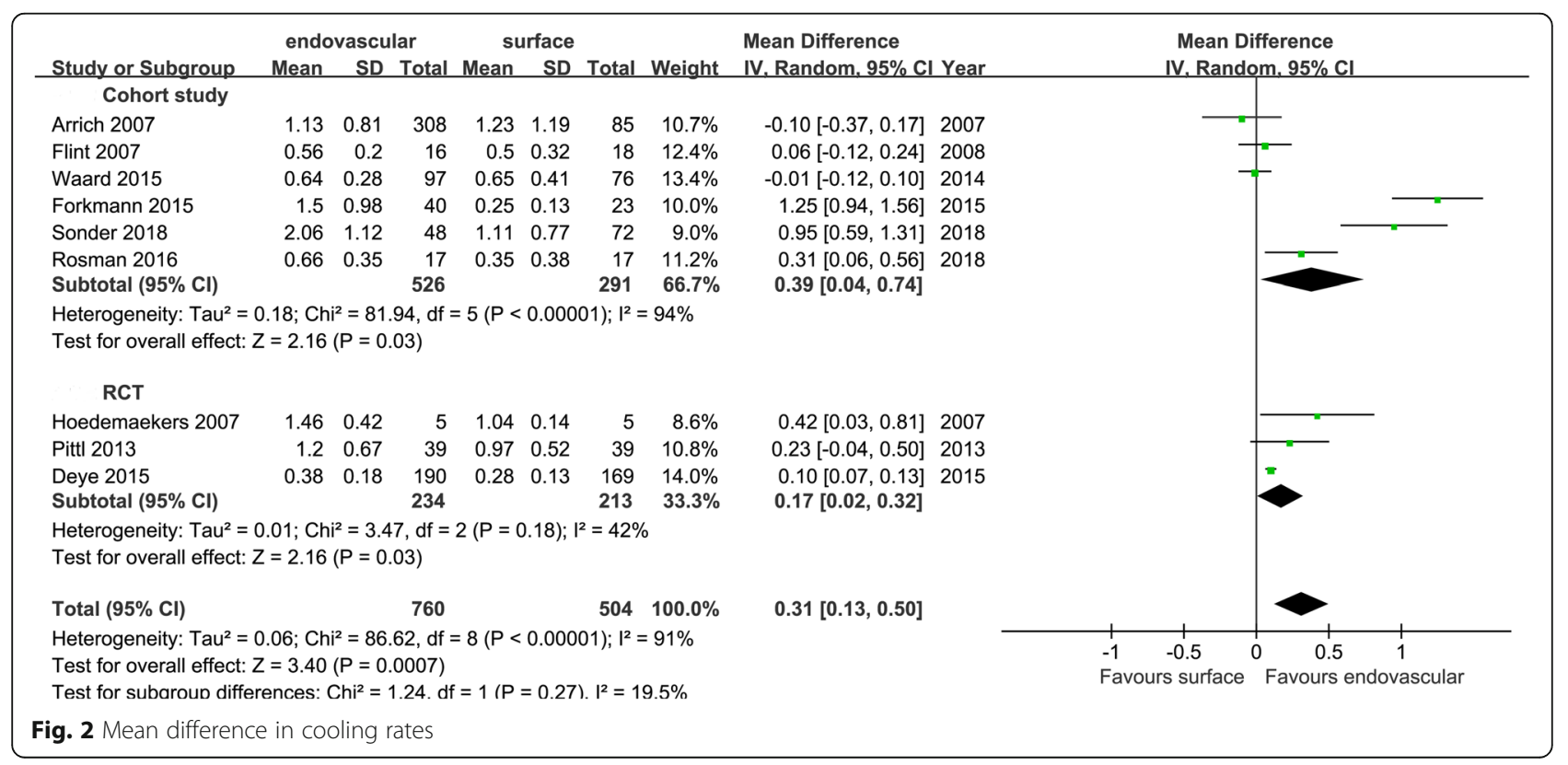




\begin{tabular}{|c|c|c|c|c|c|c|c|c|c|c|}
\hline \multirow{3}{*}{$\frac{\text { Study or Subgroup }}{\text { Cohort study }}$} & \multicolumn{3}{|c|}{ endovascular } & \multicolumn{3}{|c|}{ surface } & \multicolumn{2}{|r|}{ Mean Difference } & \multirow{2}{*}{\multicolumn{2}{|c|}{$\begin{array}{l}\text { Mean Difference } \\
\text { IV. Random, } 95 \% \mathrm{Cl}\end{array}$}} \\
\hline & \multirow[t]{2}{*}{ Mean } & \multicolumn{2}{|c|}{ SD Total } & \multirow[t]{2}{*}{ Mean } & \multirow{2}{*}{\multicolumn{3}{|c|}{ SD Total Weight }} & \multirow{2}{*}{ IV. Random. $95 \% \mathrm{Cl}$ Year } & & \\
\hline & & & & & & & & & & \\
\hline Flemming 2006 & 208.8 & 36 & 31 & 552 & 72 & 49 & $7.7 \%$ & $-343.20[-367.01,-319.39] 2006$ & - & \\
\hline Flink 2008 & 154 & 97 & 26 & 268 & 95 & 23 & $7.4 \%$ & $-114.00[-167.83,-60.17] 2008$ & & \\
\hline Ferreira 2009 & 150 & 108 & 24 & 270 & 120 & 25 & $7.3 \%$ & $-120.00[-183.87,-56.13] 2009$ & & \\
\hline Gillis 2010 & 321 & 198 & 42 & 366 & 288 & 41 & $6.7 \%$ & $-45.00[-151.57,61.57] 2010$ & & \\
\hline Caulfield 2011 & 259.8 & 151.2 & 26 & 280.2 & 155.4 & 15 & $6.9 \%$ & $-20.40[-118.19,77.39] 2011$ & & \\
\hline Tomte 2011 & 176.67 & 125.93 & 56 & 164.33 & 116.3 & 81 & $7.5 \%$ & $12.34[-29.24,53.92] 2011$ & & - \\
\hline Knapik 2011 & 378 & 258 & 19 & 240 & 192 & 11 & $5.8 \%$ & $138.00[-24.27,300.27] 2011$ & & \\
\hline Waard 2015 & 180 & 88.89 & 97 & 196.67 & 130.37 & 76 & $7.6 \%$ & $-16.67[-50.90,17.56] 2014$ & & \\
\hline Oh 2015 & 209.4 & 15.4 & 180 & 235.3 & 18 & 180 & $7.7 \%$ & $-25.90[-29.36,-22.44] 2015$ & $=$ & \\
\hline Forkmann 2015 & 158 & 77 & 40 & 436 & 141 & 23 & $7.3 \%$ & $-278.00[-340.37,-215.63] 2015$ & & \\
\hline Rosman 2016 & 240 & 88.8 & 16 & 420 & 311.4 & 17 & $5.9 \%$ & $-180.00[-334.29,-25.71] 2018$ & & \\
\hline Subtotal $(95 \% \mathrm{Cl})$ & & & 557 & & & 541 & $77.9 \%$ & $-93.83[-187.37,-0.29]$ & & \\
\hline \multicolumn{11}{|c|}{$\begin{array}{l}\text { Heterogeneity: } \text { Tau }^{2}=23222.74 ; \mathrm{Chi}^{2}=756.46, \mathrm{df}=10(\mathrm{P}<0.00001) ; \mathrm{I}^{2}=99 \% \\
\text { Test for overall effect: } Z=1.97(\mathrm{P}=0.05)\end{array}$} \\
\hline \multicolumn{11}{|l|}{ RCT } \\
\hline Pittl 2013 & 220 & 133.3 & 39 & 270 & 155.6 & 39 & $7.3 \%$ & $-50.00[-114.30,14.30] 2013$ & & \\
\hline Deye 2015 & 334 & 124.4 & 194 & 504 & 297.8 & 177 & $7.5 \%$ & $-170.00[-217.24,-122.76] 2015$ & & \\
\hline Look 2017 & 127.4 & 101.7 & 22 & 135.5 & 123 & 20 & $7.3 \%$ & $-8.10[-76.74,60.54] 2017$ & & \\
\hline Subtotal $(95 \% \mathrm{Cl})$ & & & 255 & & & 236 & $22.1 \%$ & $-78.39[-180.62,23.83]$ & & \\
\hline \multicolumn{11}{|c|}{$\begin{array}{l}\text { Heterogeneity: } \text { Tau }^{2}=7209.42 ; \mathrm{Chi}^{2}=17.64, \mathrm{df}=2(P=0.0001) ;\left.\right|^{2}=89 \% \\
\text { Test for overall effect: } Z=1.50(P=0.13)\end{array}$} \\
\hline \multirow{2}{*}{\multicolumn{4}{|c|}{$\begin{array}{l}\text { Total }(95 \% \mathrm{Cl}) \\
\text { Heterogeneity: } \text { Tau }^{2}=20058.27 ; \mathrm{Chi}^{2}=789.26 \\
\text { Test for overall effect: } Z=2.30(P=0.02) \\
\text { Test for subaroun differences: } \mathrm{Ch}^{2}=0.05 . \mathrm{df}=\end{array}$}} & & & 777 & $100.0 \%$ & $-90.45[-167.57,-13.33]$ & & \\
\hline & & & & $\begin{array}{l}\mathrm{df}=13 \\
1 \mathrm{f}=0.8\end{array}$ & $\begin{array}{l}(P<0.00 \\
831.1^{2}=\end{array}$ & $\begin{array}{l}001) ; I^{2} \\
\%\end{array}$ & $=98 \%$ & & $\begin{array}{cc}-200 & -100 \\
\text { Favours endovascular }\end{array}$ & $\begin{array}{ccc}0 & 100 & 200 \\
\text { Favours surface }\end{array}$ \\
\hline \multicolumn{9}{|c|}{ Fig. 3 Mean difference in induced cooling times } & & \\
\hline
\end{tabular}

superior to $\mathrm{SC}$ in the cooling rate in both the cohort study group and the RCT group. In terms of the induced cooling time and the number of patients achieving the target temperature, EC was superior to SC in the cohort study group, and there was no statistical difference between the two cooling groups in the RCT group. The aggregated results showed that EC was superior to $\mathrm{SC}$ in the cooling efficiency (Figs. 2, 3, and 4).
Seventeen studies that included data on temperature maintenance stability showed that EC was superior to $\mathrm{SC}$ in the maintenance times of $\mathrm{TH}(\mathrm{MD}=2.35[1.22$, 3.48], $p<0.01, I^{2}=94 \%$ ), temperature fluctuations control $\left(\mathrm{MD}=-0.68[-1.03,0.33], p<0.01, I^{2}=61 \%\right)$, and excessive temperature drop control $(\mathrm{RR}=0.33[0.23$, $\left.0.49], p<0.01, I^{2}=0 \%\right)$. There was no significant difference in body temperature during the maintenance phase

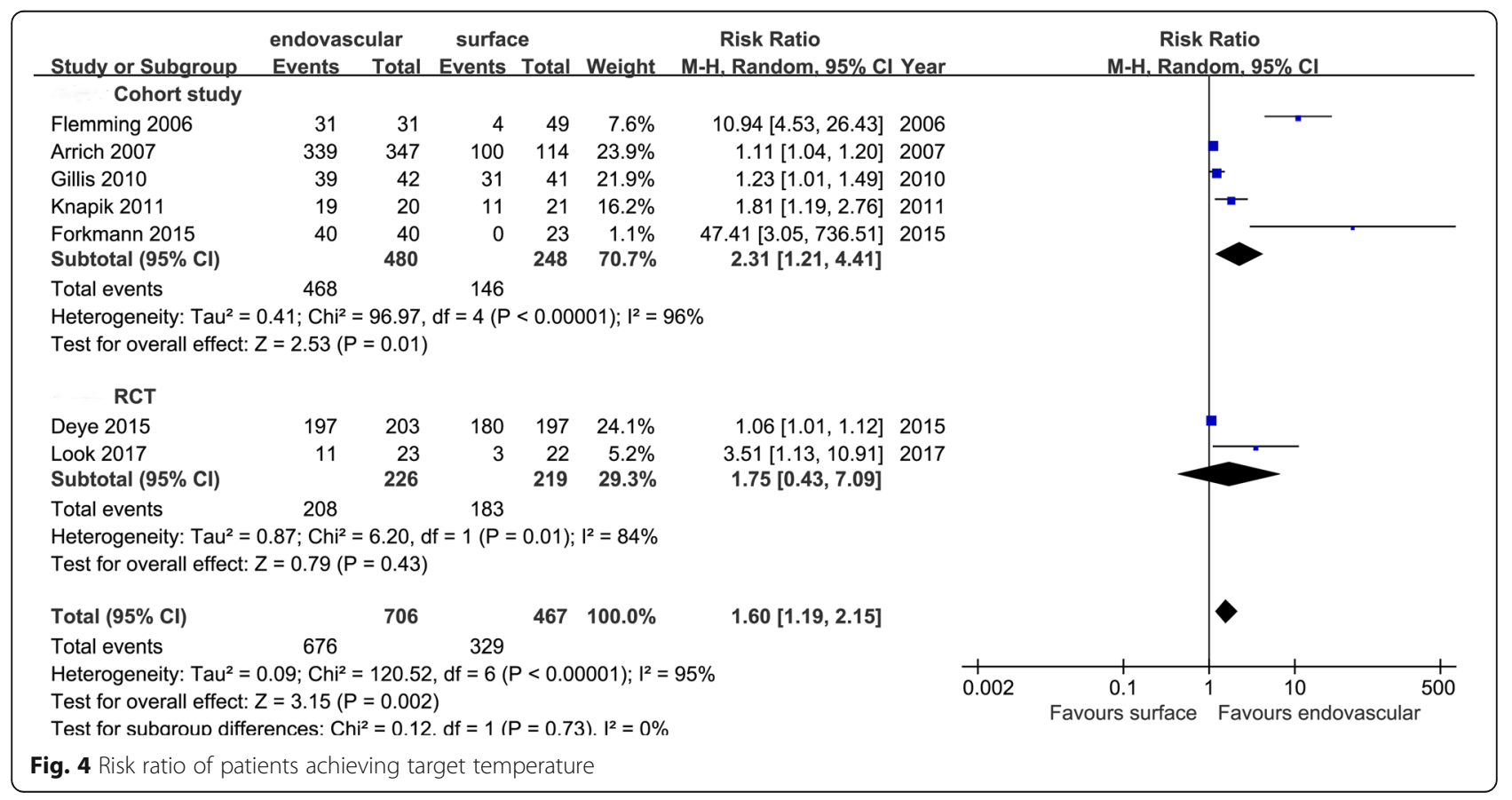




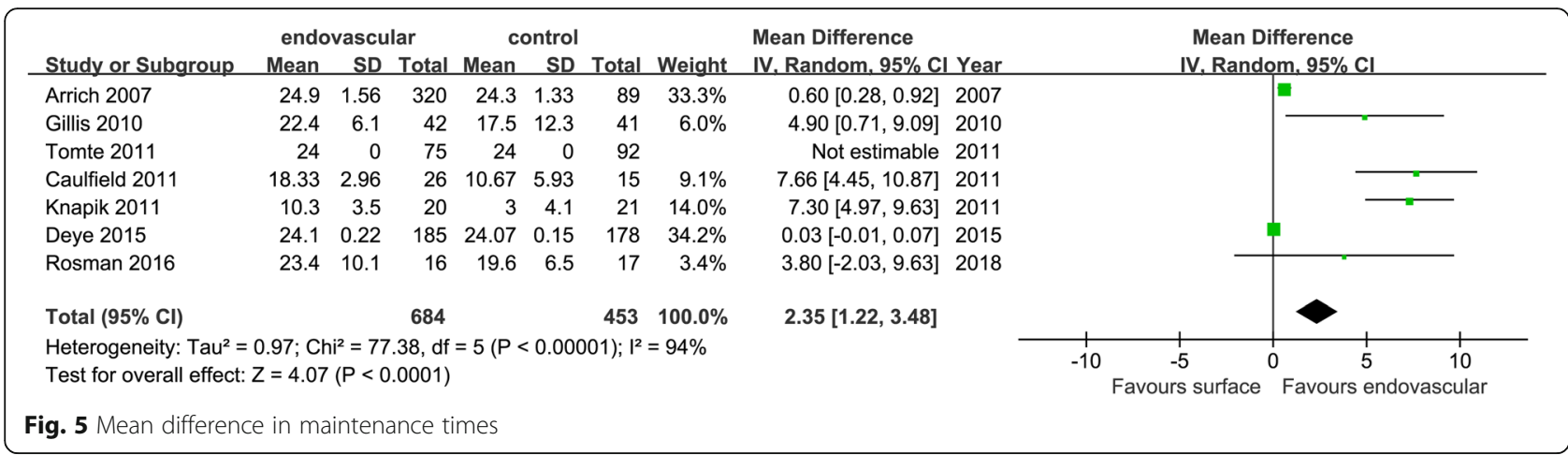

$\left(\mathrm{MD}=-0.44[-1.50,0.62], p=0.42, I^{2}=99 \%\right)$ (Figs. 5, 6, 7 , and 8).

Only 5 studies reported data on the rewarming process, and the results showed no difference between the two groups in rewarming rates $(\mathrm{MD}=-0.11[-0.42$, 0.19], $\left.p=0.46, I^{2}=92 \%\right)$; rewarming times $(\mathrm{MD}=-1.34$ $\left.[-3.54,0.85], p=0.23, I^{2}=92 \%\right)$; and rebound hyperthermia $\left(\mathrm{RR}=0.86[0.66,1.13], p=0.28, I^{2}=15 \%\right)$ (Figs. 9, 10, and 11).

The four outcomes were analyzed according to the original study type, namely, cohort studies and RCTs. Only 5 cohort studies reported the length of stay in the ICU. The results showed that EC could reduce the length of stay in the ICU $(\mathrm{MD}=-1.83[-3.45,-0.21], p=0.03$, $I^{2}=49 \%$ ) (Fig. 12); no RCTs reported this outcome. There was no significant difference in the ICU survival rate or hospital survival rate between the two methods of cooling, and the results within groups were consistent with the aggregated results: the ICU survival rate in cohort studies, $\mathrm{RR}=1.20[0.97,1.50], p=0.09, I^{2}=0 \%$; in RCTs, $R R=9.00[0.61,133.08], p=0.11$; and in the aggregated results the $\mathrm{RR}=1.22[0.98,1.52], p=0.07, I^{2}=$ 0\% (Fig. 13).

In the cohort studies, the hospital survival rate, $\mathrm{RR}=$ $1.01[0.94,1.09], p=0.74, I^{2}=0 \%$; in the RCTs, $\mathrm{RR}=$ $1.14[0.93,1.38], p=0.21$; and in the aggregated results, $\mathrm{RR}=1.02[0.96,1.09], p=0.46, I^{2}=0 \%$ (Fig. 14).

In the cohort studies, the favorable neurological function at discharge, $\mathrm{RR}=1.13[1.01,1.27], p=0.03, I^{2}=0 \%$, in RCTs, $R R=1.26[0.96,1.64], p=0.09$; and in the aggregated results, $\mathrm{RR}=1.15[1.04,1.28], p<0.01, I^{2}=$ $0 \%$, and there was no heterogeneity within or between groups $\left(I^{2}=0 \%\right)$ (Fig. 15). The cohort studies showed that EC was better than SC, and the RCTs results showed no significant difference between the two groups. The aggregated results showed that EC can make more patients achieve the favorable neurological function. The clinical outcome rates are shown in Table 4, which shows the final outcome of EC and SC methods and the comparative results between the two main cooling ways of SC (ArcticSun, non-ArcticSun) and the cooling ways of EC.

Because there is a special type of surface cooling equipment, namely, ArcticSun equipment, it added temperature feedback loop technology compared with other surface cooling equipment, which may greatly improve the temperature controllability. Therefore, in order to further compare the differences between the use of traditional surface cooling equipment (i.e., non-ArcticSun) and EC equipment, we performed a subgroup analysis according to the surface cooling technology of ArcticSun and non-ArcticSun. The results showed that EC was superior to non-ArcticSun in cooling efficiency (Additional files 1, 2, and 3). In terms of patient outcomes, there was no statistical difference in ICU survival rate, ICU hospital stay, and hospital survival rate between the two equipment, but EC improved patients' rates of neurologically intact survival $\left(\mathrm{RR}=1.16[1.01,1.35], \quad p=0.04, I^{2}=0 \%\right)$ (Additional files 4, 5, 6, and 7).

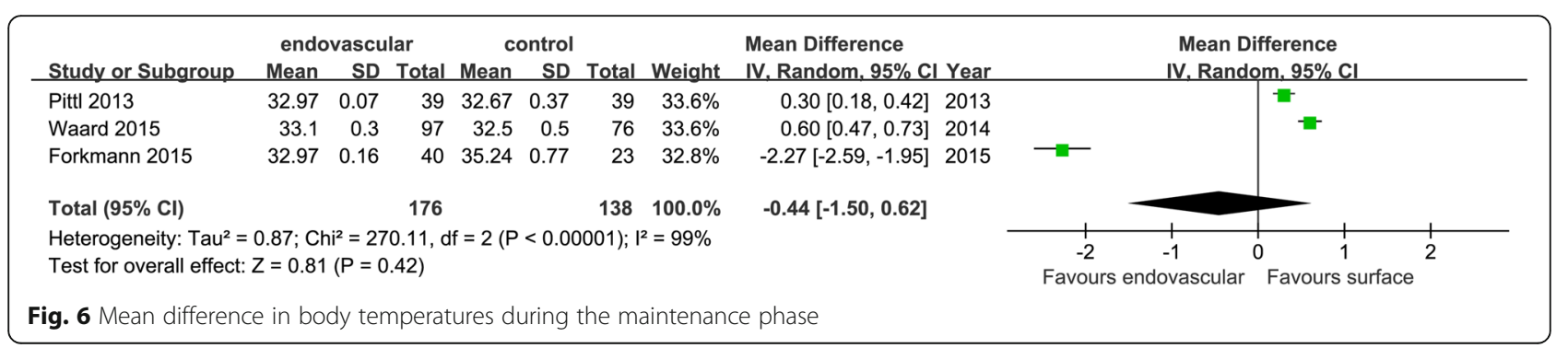




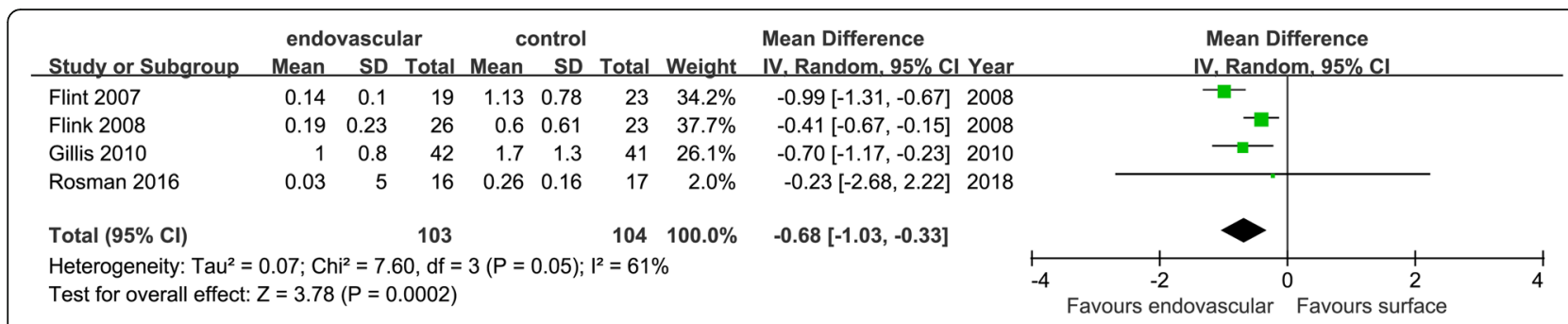

Fig. 7 Mean difference in body temperature fluctuations

\section{Risk assessment}

The quality of the cohort studies was assessed using the Newcastle-Ottawa Scale (NOS) (Table 5), which included the selection of the cohort, comparability between groups, and results. The quality of RCTs was assessed using the Cochrane Risk Bias Evaluation Tool (Table 6), which included random sequence generation, allocation concealment, blinding of participants and personnel, blinding of outcome assessment, incomplete outcome data, selective reporting, and other sources of bias. Finally, funnel charts were used to observe whether there was publication bias (Fig. 16).

\section{Discussion}

In 2010, based on various studies on $\mathrm{TH}$, the AHA recommended that after resuscitation, unconscious OHCA survivors should be treated with mild hypothermia after ROSC to reduce the body temperature to $32-34{ }^{\circ} \mathrm{C}$ and maintain it there for $12-24 \mathrm{~h}$ [48]. Further studies have shown that OHCA patients with an initial shockable rhythm can achieve better outcomes through TH. However, these studies do not provide conclusions and recommendations regarding the common cooling methods, such as SC and EC. Therefore, this meta-analysis compared two common cooling methods (SC and EC) that are currently used to induce $\mathrm{TH}$ to determine which is better.

To reduce the occurrence of correlation bias, we took the following measures in the analytical process. (1) Compared with the SC technology, the initial startup time of EC may be delayed because of its professionalism and difficulty. In order to ensure the accuracy of the results, we further analyzed the time from the start of patients' cardiac arrest to achieving the target temperature, and found that under this calculation method, there was no significant difference between the two cooling methods in the time from the start of patients' cardiac arrest to achieving the target temperature $(\mathrm{MD}=-46.64[-175.86,82.58])$. (2) We analyzed the obvious heterogeneity in the cooling efficiency results in the following aspects: (1) performing sensitivity analysis: we divided the surface cooling methods into two categories (ArcticSun, nonArcticSun). The comprehensive results of cooling rate, the induced cooling time, and the number of people reaching the temperature, EC was improved compared to SC (ArcticSun and non-ArcticSun) (Additional files 1, 2, and 3). At the same time, we analyzed the final outcome of the patients according to two methods of surface cooling. It was found that there was no significant difference between the Arctic-Sun

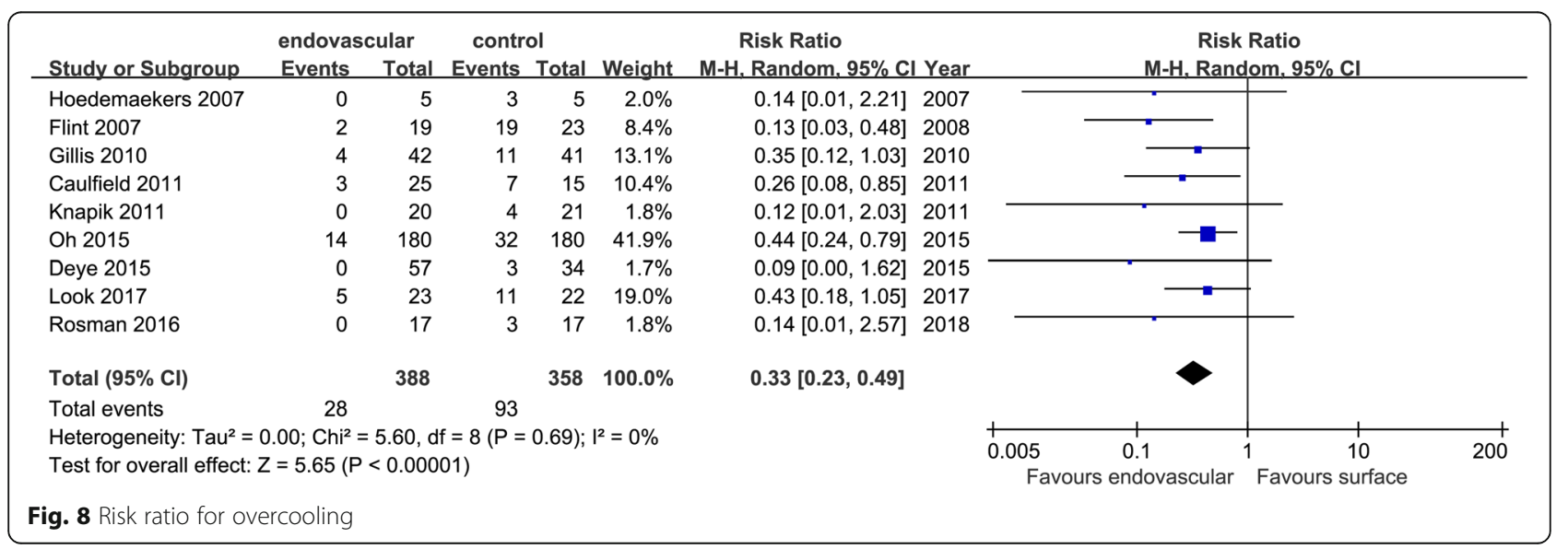




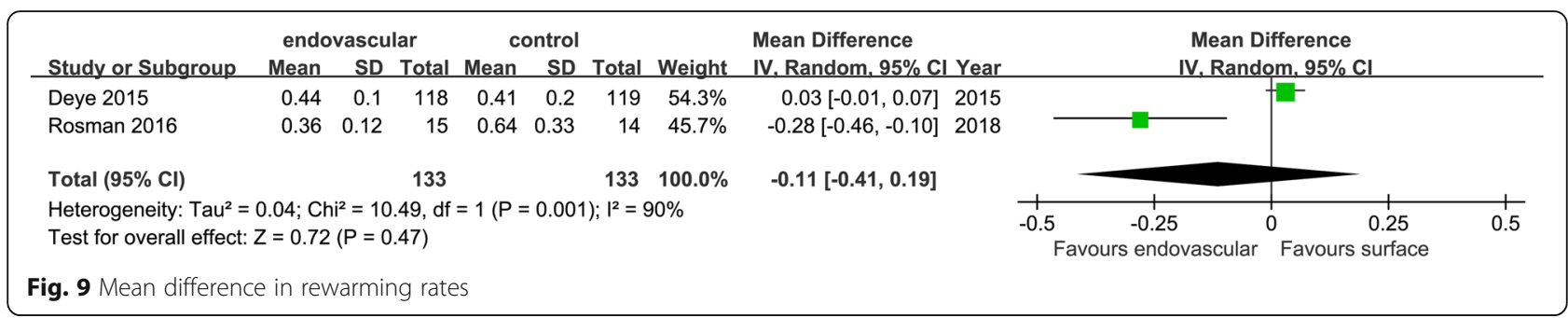

and EC in terms of the length of stay in ICU, the survival rate in ICU, the survival rate in hospital, and the prognosis of good neurological function. However, compared with non-ArcticSun, EC can improve the prognosis of neurological function in more patients (Appendix, Figs. 4, 5, 6, and 7). (2) performing sensitivity analysis in OHCA patients and patients combined with OHCA and IHCA; performing sensitivity analysis in patients with CA caused by cardiogenic factors and patients with cardiogenic and non-cardiac CA. The results showed that the heterogeneity was not significantly improved. Therefore, we further adopted the excluding methods to study high heterogeneity between researches. We excluded the original research one by one, and found that no study has a decisive influence on high heterogeneity. The item exclusion showed that the heterogeneity only decreased from 91 to $79 \%$ in the cooling rate after the Forkman 2015 [32] study was excluded. Therefore, we conducted a more detailed analysis in the study and found that the patients in the study received immediate surface ice blanket cooling and infused less than $3 \mathrm{l}$ of ice water from the beginning of admission so as to achieve the target body temperature. We speculate that the patients in the study had already received other cooling methods before EC, which may cause differences in the cooling rate. However, before and after the study was excluded, the cooling efficiency index did not change. For the induced cooling time and the number of people reaching the targeted temperature, the heterogeneity did not improve significantly and maintained at $91-98 \%$ and $90-97 \%$, respectively after the item exclusion. Therefore, we consider that the original research included in the study covers all regions of the world and has difference in the emergency system, the way of implementing cardiopulmonary resuscitation, and the way of hypothermia treatment, which are the main reasons for the high heterogeneity. Therefore, we used a random effects model to analyze the final results to minimize the heterogeneity between studies. (3) We analyzed the characteristics of the populations included in the studies and compared the variables such as witnesses, the cause of CA (cardiac or noncardiac), initial rhythm (shockable or non-shockable), sex, and age between the two groups to rule out their possible effects on TH efficacy. (4) We compared relevant factors that may affect patient survival, such as ROSC time and the performance of CAG and PCI after admission, to reduce the impacts of confounding factors on the outcomes.

In our systematic review, we analyzed the different stages of the $\mathrm{TH}$ process and found that EC can reach the target temperature faster (average $1.07^{\circ} \mathrm{C} / \mathrm{h}$ ) than $\mathrm{SC}\left(0.71^{\circ} \mathrm{C} / \mathrm{h}\right)$. In the $\mathrm{TH}$ phase, when compared with SC, the EC may be associated with higher rate of target temperature achievement (95.8\% vs. $70.4 \%)$, have a longer maintenance times $(21.1 \mathrm{~h}$ vs. $17.6 \mathrm{~h})$, less fluctuations in body temperature $\left(0.34{ }^{\circ} \mathrm{C}\right.$ vs. $\left.0.92^{\circ} \mathrm{C}\right)$, and less incidence of overcooling $(7.2 \%$ vs. 26\%). Related studies have mentioned that EC performs better than SC in terms of controlling body

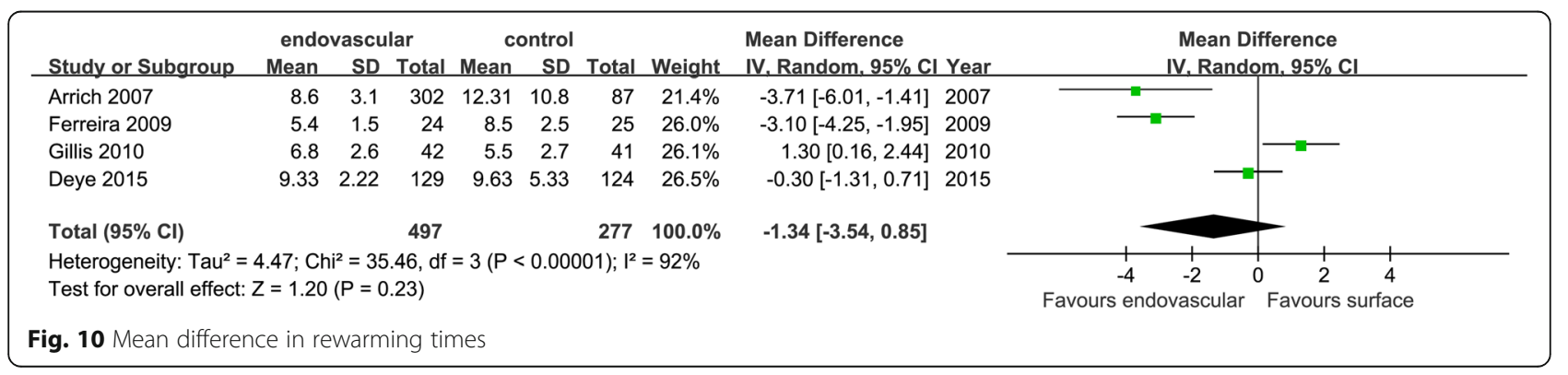




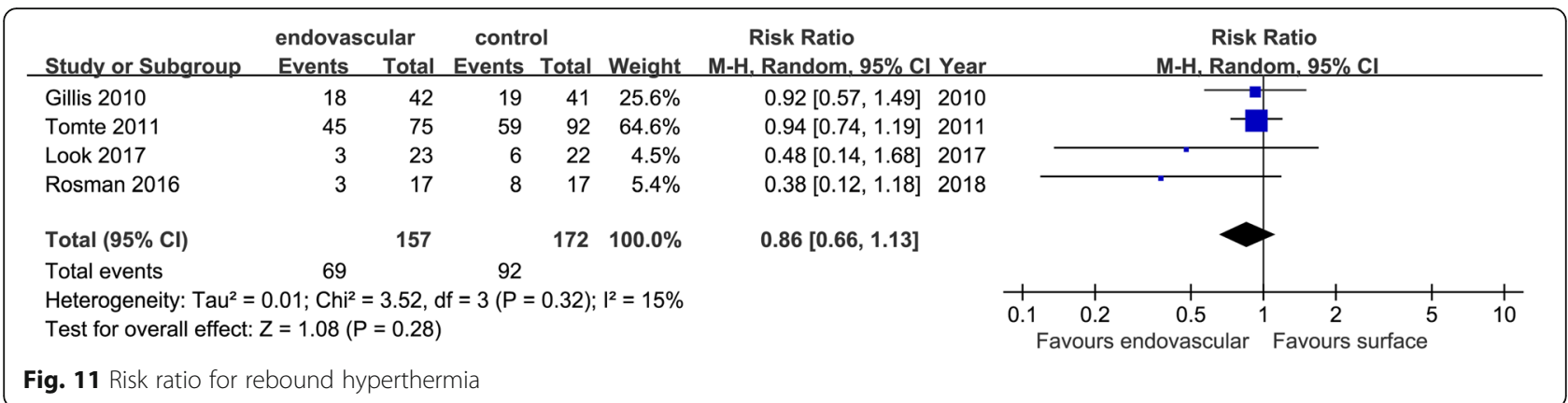

temperature and reducing body temperature fluctuations, thereby reducing the occurrence of adverse events in TH [49]. Although there was no significant difference between the two cooling methods during the rewarming period, the average rewarming speed $\left(0.4{ }^{\circ} \mathrm{C} / \mathrm{h}\right.$ vs. $\left.0.53{ }^{\circ} \mathrm{C} / \mathrm{h}\right)$ indicates that $\mathrm{EC}$ is more in line with the guidelines, which recommend a rewarming speed of 0.25 to $0.5^{\circ} \mathrm{C} / \mathrm{h}$ [10].

For the safety of patients during $\mathrm{TH}$, some studies [27-29, 31-34, 37, 39-41, 45] analyzed the major adverse events, including arrhythmias [29-32, 34, 37, 39$41,45]$, bleeding [24, 25, 28, 31, 34, 40, 41], and infection $[29,33,34,40,41]$. In addition, pneumonia [28, 29, 31, $34,40]$ was further independently analyzed. Based on the data included in the studies, we found no significant difference in the probability of arrhythmia or infection during the above hypothermia treatments, and the probability of bleeding in the EC group was higher than that in the SC group (Table 7).

Survival and prognosis outcomes: although there were no significant differences in ICU survival rates and hospital survival rates between patients receiving the two different cooling methods, EC could improve patients' neurological outcomes at discharge, which is significant for improving the relatively low survival rate and poor neurological prognosis in $\mathrm{CA}$ patients.

Different cooling methods have varying degrees of complexity and equipment-related (economic) costs.
In the actual clinical application of EC, unlike in surface cooling methods, a catheter needs to be inserted into the central vein, which is a process generally performed by the relevant technical personnel after the patient reaches the hospital, so the complexity and cost are high. However, the complexity of inserting central venous cannula is relative because patients in the ICU require central venous access after cardiac arrest resuscitation anyway, and most patients with CA due to cardiac factors will receive CAG. Our meta-analysis also showed that more than $50 \%$ of CA patients underwent CAG after admission, which is also beneficial for catheter placement during hypothermia. Although the current EC device is more expensive than other SC devices, according to the meta-analysis results, the EC method can reduce the length of stay in the ICU in comparison with the SC method. Hence, EC can reduce the economic burden to some extent due to the high cost associated with staying in the ICU.

\section{Limitations}

(1) The original studies included did not clearly distinguish the characteristics of the included population, e.g., causes of cardiac arrest (cardiac/noncardiac), initial rhythm of cardiac arrest (shockable/ non-shockable), and the location of cardiac arrest (in hospital, out-of-hospital). Therefore, we cannot make

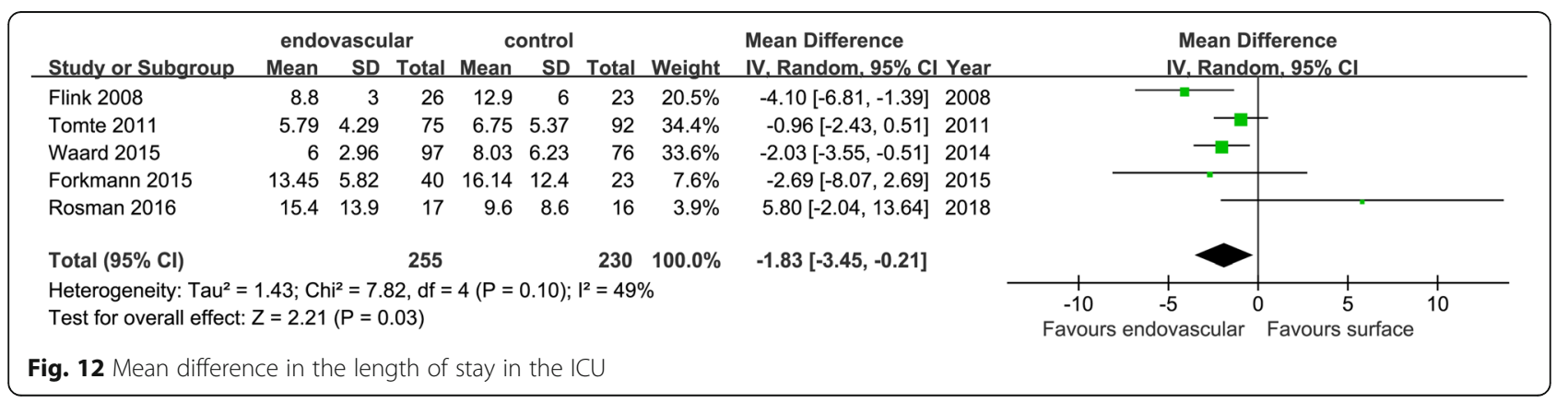




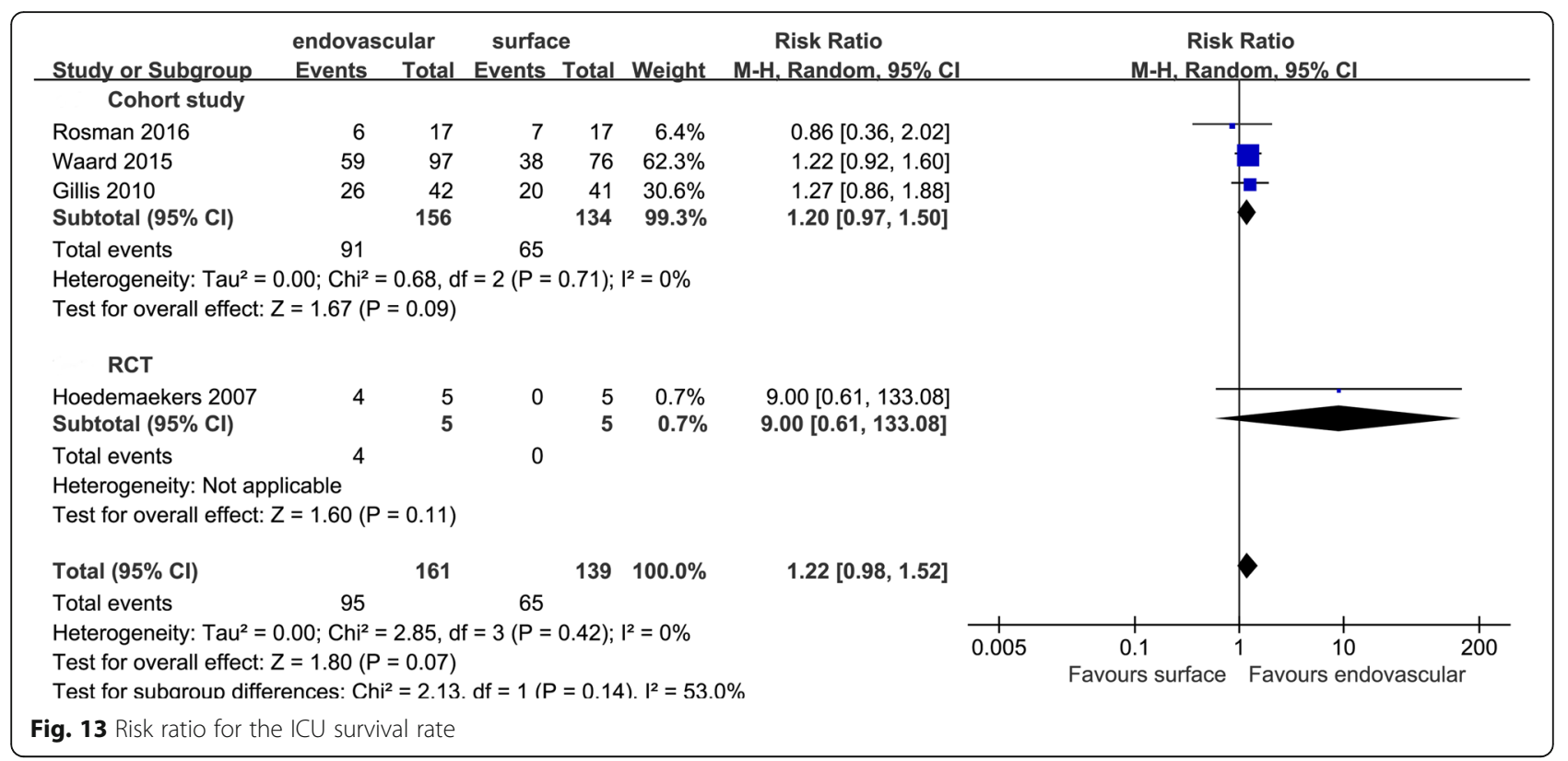

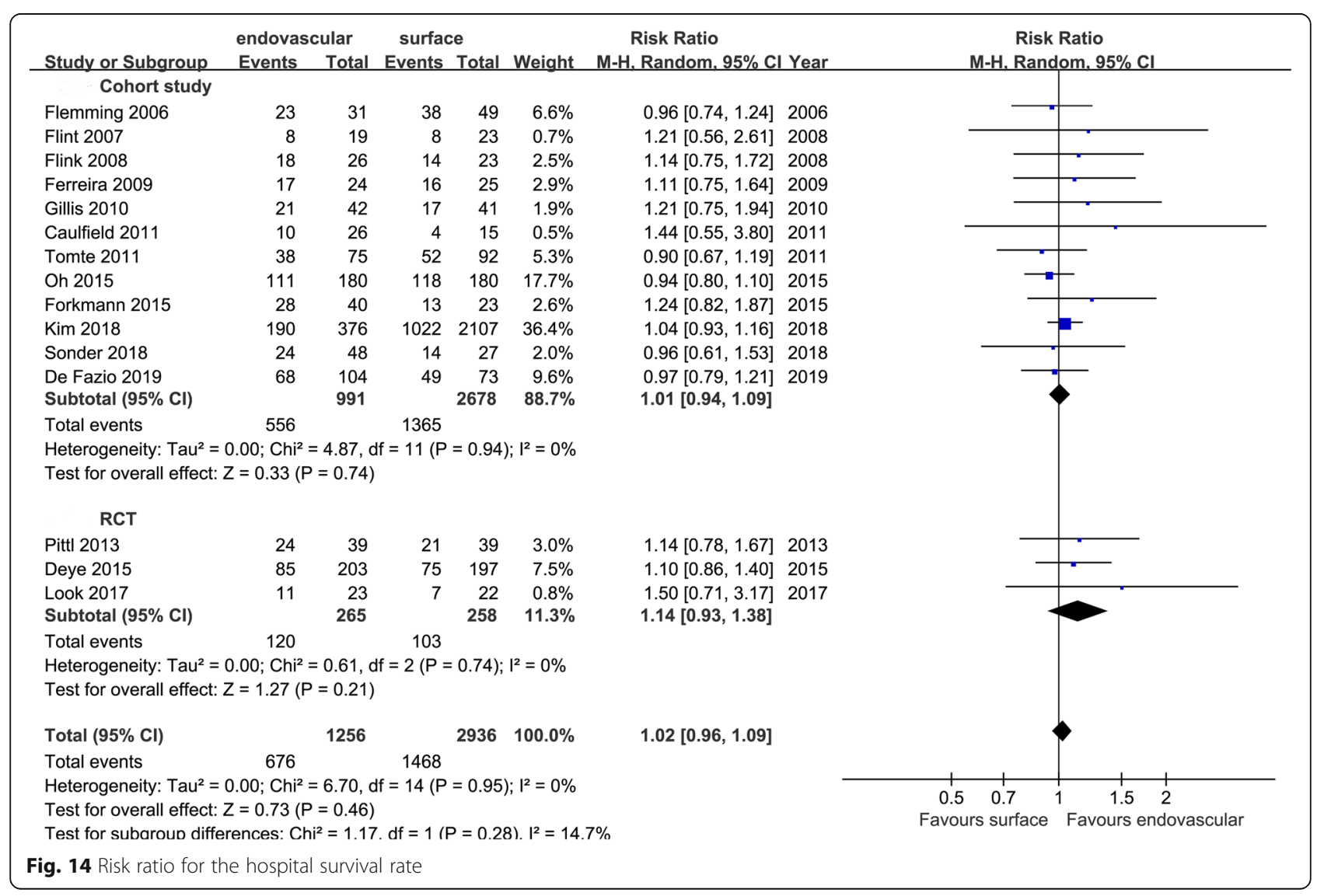




\begin{tabular}{|c|c|c|c|c|c|c|c|c|}
\hline \multirow{3}{*}{$\begin{array}{r}\text { Study or Subgroup } \\
\text { Cohort study }\end{array}$} & \multicolumn{2}{|c|}{ endovascular } & & \multicolumn{2}{|r|}{ Risk Ratio } & \multirow{2}{*}{\multicolumn{2}{|c|}{$\begin{array}{l}\text { Risk Ratio } \\
\text { M-H. Random, } 95 \% \mathrm{Cl} \\
\end{array}$}} \\
\hline & Events & Total & \multicolumn{2}{|c|}{$\begin{array}{l}\text { surface } \\
\text { Events Total }\end{array}$} & Weight & M-H, Random, 95\% Cl Year & & \\
\hline & & & & & & & & \\
\hline Ferreira 2009 & 15 & 24 & 10 & 25 & $3.3 \%$ & $1.56[0.88,2.77] 2009$ & & \\
\hline Gillis 2010 & 18 & 42 & 16 & 41 & $4.0 \%$ & $1.10[0.65,1.84] 2010$ & & \\
\hline Tomte 2011 & 34 & 75 & 34 & 90 & $8.2 \%$ & $1.20[0.83,1.73] 2011$ & & \\
\hline Oh 2015 & 63 & 180 & 54 & 180 & $12.1 \%$ & $1.17[0.87,1.57] 2015$ & & \\
\hline Sonder 2018 & 23 & 48 & 14 & 27 & $4.9 \%$ & $0.92[0.58,1.48] 2018$ & & \\
\hline Kim 2018 & 101 & 376 & 486 & 2107 & $31.9 \%$ & $1.16[0.97,1.40] 2018$ & & \\
\hline De Fazio 2019 & 67 & 104 & 45 & 73 & $20.4 \%$ & $1.05[0.83,1.32] 2019$ & & \\
\hline Subtotal $(95 \% \mathrm{Cl})$ & & 849 & & 2543 & $84.8 \%$ & $1.13[1.01,1.27]$ & & \\
\hline Total events & 321 & & 659 & & & & & \\
\hline \multirow{2}{*}{\multicolumn{9}{|c|}{$\begin{array}{l}\text { Heterogeneity: } \mathrm{Tau}^{2}=0.00 ; \mathrm{Chi}^{2}=2.68, \mathrm{df}=6(\mathrm{P}=0.85) ; \mathrm{I}^{2}=0 \% \\
\text { Test for overall effect: } Z=2.17(\mathrm{P}=0.03)\end{array}$}} \\
\hline & & & & & & & & \\
\hline \multicolumn{9}{|l|}{ RCT } \\
\hline Pittl 2013 & 14 & 39 & 14 & 39 & $3.1 \%$ & $1.00[0.55,1.81] 2013$ & & \\
\hline Deye 2015 & 66 & 191 & 47 & 181 & $11.0 \%$ & $1.33[0.97,1.82] 2015$ & & \\
\hline Look 2017 & 7 & 23 & 5 & 22 & $1.1 \%$ & $1.34[0.50,3.60] 2017$ & & \\
\hline Subtotal $(95 \% \mathrm{Cl})$ & & 253 & & 242 & $15.2 \%$ & $1.26[0.96,1.64]$ & & \\
\hline Total events & 87 & & 66 & & & & & \\
\hline \multirow{2}{*}{\multicolumn{9}{|c|}{$\begin{array}{l}\text { Heterogeneity: } \text { Tau }^{2}=0.00 ; \mathrm{Chi}^{2}=0.71, \mathrm{df}=2(P=0.70) ;\left.\right|^{2}=0 \% \\
\text { Test for overall effect: } Z=1.67(P=0.09)\end{array}$}} \\
\hline & & & & & & & & \\
\hline Total $(95 \% \mathrm{Cl})$ & & 1102 & & 2785 & $100.0 \%$ & $1.15[1.04,1.28]$ & & 1 \\
\hline Total events & 408 & & 725 & & & & & \\
\hline $\begin{array}{l}\text { Heterogeneity: } \mathrm{Tau}^{2}= \\
\text { Test for overall effect: } \\
\text { Test for subaroun diffe }\end{array}$ & $\begin{array}{l}0.00 ; \mathrm{Chi}^{2} \\
\mathrm{Z}=2.65(\mathrm{P} \\
\text { rences: } \mathrm{Ch}\end{array}$ & $\begin{array}{l}=3.90, \mathrm{df} \\
=0.008) \\
j^{2}=0.49 .\end{array}$ & $\begin{array}{l}\mathrm{lf}=9(\mathrm{P}= \\
\mathrm{df}=1(\mathrm{~F}\end{array}$ & $\begin{array}{l}=0.92) ; \\
P=0.48\end{array}$ & $\begin{array}{l}1^{2}=0 \% \\
\text { 8). }\left.\right|^{2}=0 \%\end{array}$ & & $\begin{array}{cc}0.5 & 0.7 \\
\text { Favours surface }\end{array}$ & 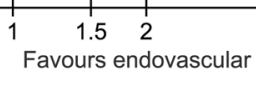 \\
\hline Fig. 15 Risk ratio for $g$ & ood neurc & logical $f$ & function & & & & & \\
\hline
\end{tabular}

a clear judgment on the possible interference effects to subsequent treatments based on the above factors. At the same time, we can only evaluate the subhypothermia after a sudden cardiac arrest in a broad sense, and cannot make a proper evaluation of the population with the above single factor characteristics.

(2) The research included is from more than 10 countries around the world, and the differences caused by factors such as different regions, races, and economic levels will inevitably cause heterogeneity between studies to varying degrees.

(3) This study only included four RCTs, and the level of evidence was weak; more high-quality studies are needed to confirm these findings.

\section{Conclusions}

Surface cooling includes a range of equipment, from simple ice packs to complex machines that use recycled coolants and automatic feedback, which have low cost, low invasiveness, and easy operation; however, it is sometimes difficult to achieve the target temperature in clinical practice using these methods, so the therapeutic effect of $\mathrm{TH}$ on post-resuscitation cannot be achieved. Although there was no significant difference in the time from the start of patients' cardiac arrest to achieving the target temperature between the two cooling methods, the final outcome of the patient showed that patients in the EC group had a shorter ICU hospitalization and a better neurological prognosis than those in the SC group.

Table 4 The rates of clinical outcomes

\begin{tabular}{lllll}
\hline Cooling methods & & ICU survive rate & Hospital survive rate & Good neurological function \\
\hline EC/SC & EC & $96 / 165(58.2 \%)$ & $676 / 1256(53.8 \%)$ & $408 / 1102(37 \%)$ \\
& SC & $65 / 139(46.8 \%)$ & $1468 / 2936(50 \%)$ & $725 / 2695(26.9 \%)$ \\
EC/ArcticSun & EC & $4 / 5(80 \%)$ & $249 / 486(51.2 \%)$ & $179 / 561(31.9 \%)$ \\
& ArcticSun & $0 / 5(0 \%)$ & $1064 / 2195(48.5)$ & $553 / 2285(24.2 \%)$ \\
EC/non-ArcticSun & EC & $91 / 156(58.3 \%)$ & $389 / 695(56 \%)$ & $229 / 541(42.3 \%)$ \\
& Non-ArcticSun & $65 / 134(48.5 \%)$ & $352 / 649(54.2 \%)$ & $172 / 500(34.4 \%)$ \\
\hline
\end{tabular}




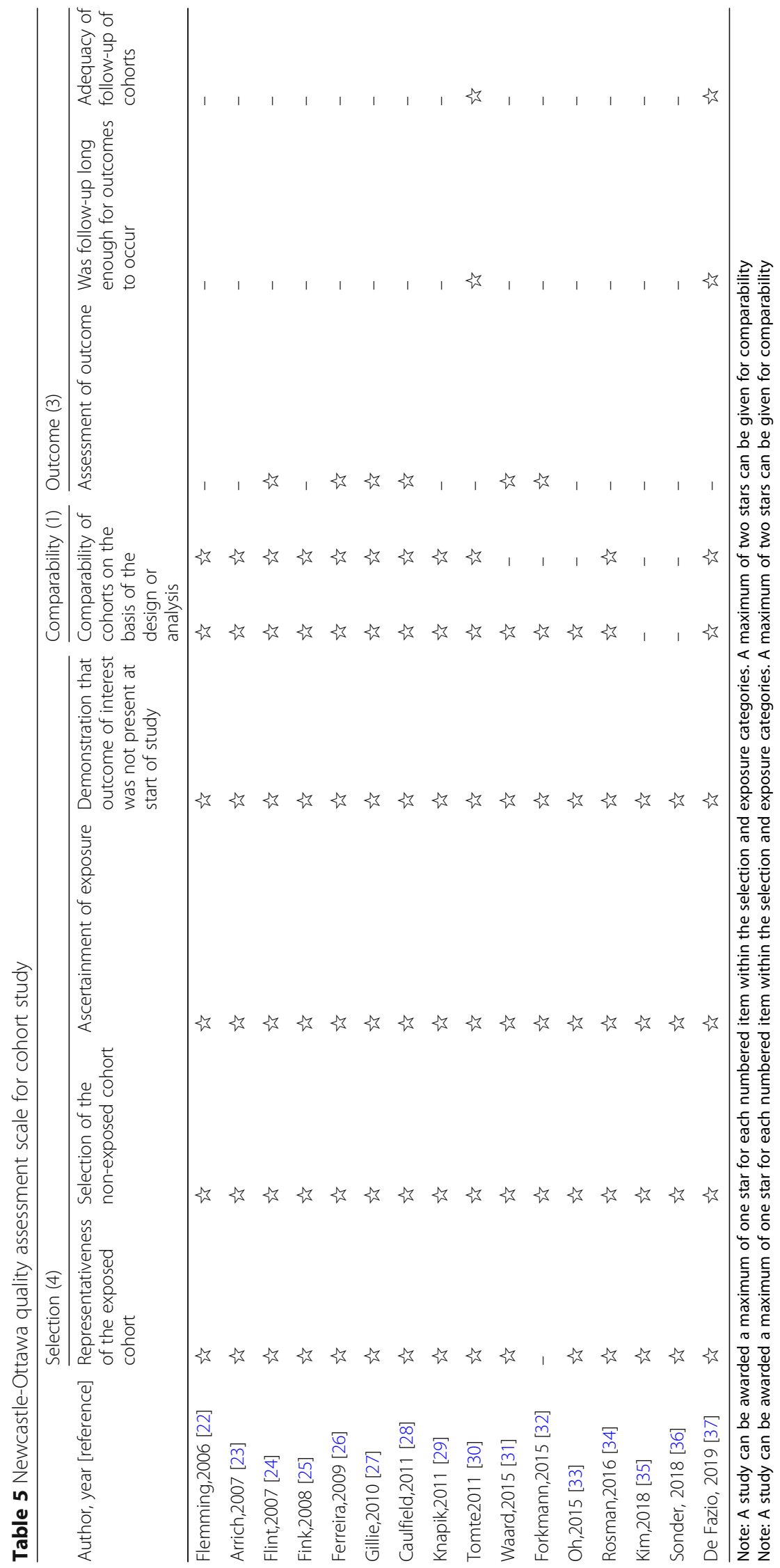


Table 6 Cochrane Risk bias assessment tool for RCTs

\begin{tabular}{|c|c|c|c|c|c|c|c|}
\hline Author, year [reference] & $\begin{array}{l}\text { Sequence } \\
\text { generation }\end{array}$ & $\begin{array}{l}\text { Allocation } \\
\text { concealment }\end{array}$ & Blinding & Incomplete data & $\begin{array}{l}\text { Selective } \\
\text { reporting }\end{array}$ & Other bias & $\begin{array}{l}\text { Summary of } \\
\text { the risk of bias }\end{array}$ \\
\hline Hoedemaekers, 2007 [38] & Unclear & Unclear & Unclear & Low & High & Low & High \\
\hline Pittl, 2013 [39] & High & Unclear & Unclear & Low & Low & High & High \\
\hline Deye, 2015 [40] & Low & Low & Unclear & Low & Low & Low & Low \\
\hline Look, 2017 [41] & Low & Low & Unclear & Low & Low & Unclear & High \\
\hline
\end{tabular}

Therefore, we believe that because of the advantages in the precise temperature control, the rapid and smooth cooling and the slow and gentle rewarming process, EC is better than SC in the effective temperature control, thus making the EC method have a greater advantage in the treatment of patients. However, because ArcticSun in the surface cooling equipment has a temperature feedback loop system, it realizes temperature feedback control compared to non-ArcticSun. After further analysis, it is found that ArcticSun is inferior to EC equipment in cooling efficiency, but both have no significant difference in ICU hospitalized time, ICU survival rate, hospital survival rate, and good neurological outcome. EC not only has better cooling efficiency than non-ArcticSun, but also improves patients' rate of neurologically intact survival. Therefore, we consider that the EC device can improve the outcome of patients' neurological function compared with non-Arcticsun's surface cooling device, but there is no obvious difference compared with ArcticSun which has temperature feedback loop system, so further research is needed

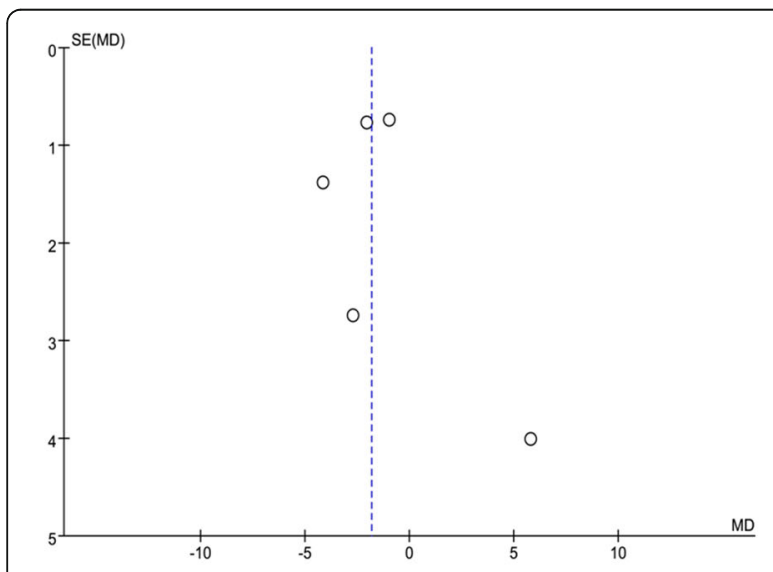

Figure A:Funnel plot for the length of stay in ICU

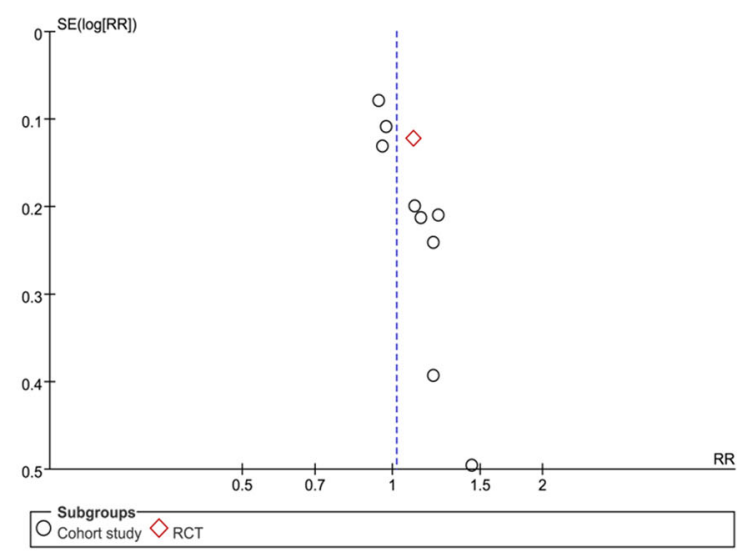

Figure C:Funnel plot for survival rate in hospital

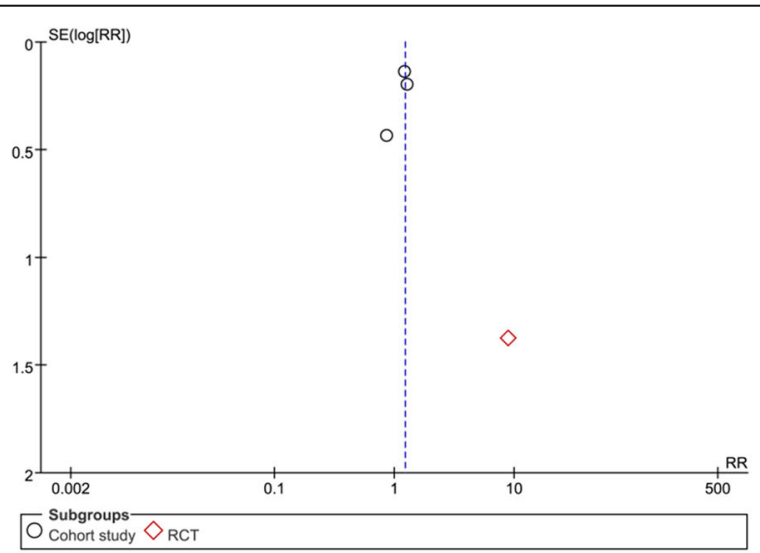

Figure B:Funnel plot for survival rate in the ICU

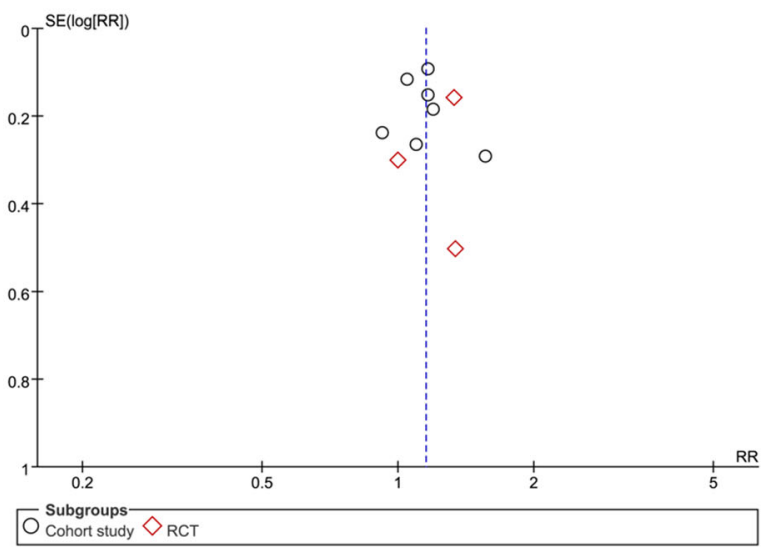

Figure D:Funnel plot for good neurological function

Fig. 16 Funnel plots 
Table 7 The adverse events during TH in the two groups

\begin{tabular}{lll}
\hline Adverse events & Risk ratio $(95 \%$ confidence interval $)$ & $p$ \\
\hline Arrhythmia & $1.01(0.83,1.23)$ & .940 \\
Infection & $1.09(0.80,1.47)$ & .590 \\
Pneumonia & $1.07(0.95,1.12)$ & .260 \\
Bleeding & $1.60(1.13,2.27)$ & $<0.01$ \\
\hline
\end{tabular}

to compare the differences between the surface cooling technology controlled by the feedback loop system and the EC technology.

\section{Supplementary information}

Supplementary information accompanies this paper at https://doi.org/10. 1186/s13054-020-2731-z.

Additional file 1. Mean difference in cooling rates (ArcticSun, Non-

ArcticSun).

Additional file 2. Risk ratio of patients achieving target temperature (ArcticSun,Non-ArcticSun).

Additional file 3. Mean difference in induced cooling times (ArcticSun,Non-ArcticSun).

Additional file 4. Mean difference in the length of stay in the ICU (ArcticSun,Non-ArcticSun).

Additional file 5. Risk ratio for the ICU survival rate (ArcticSun,NonArcticSun)

Additional file 6. Risk ratio for the hospital survival rate (ArcticSun,NonArcticSun).

Additional file 7. Risk ratio for good neurological function (ArcticSun,Non-ArcticSun).

\section{Acknowledgements}

This work was supported by the National Natural Science Foundation of China (81460291) and the Guizhou Province Science and Technology Fund (Qiankehe J word [2014] no. 2183, LH word [2015]7552).

\section{Authors' contributions}

$X L L, Z Y Z, M H Z$, and $H T$ analyzed the data and wrote the paper. MLF, BJK, NZ, $\mathrm{FTL}$, and LZW designed the study and revised the paper. All authors read and approved the final manuscript

\section{Funding}

This work was supported by the National Natural Science Foundation of China (81460291) and the Guizhou Province Science and Technology Fund (Qiankehe J word [2014] no. 2183, LH word [2015]7552).

\section{Availability of data and materials}

All data generated or analyzed during this study are included in this published article.

\section{Ethics approval and consent to participate}

Not applicable.

\section{Consent for publication}

Not applicable.

\section{Competing interests}

The authors declare that they have no competing interests.
Received: 20 June 2019 Accepted: 10 January 2020

Published online: 28 January 2020

\section{References}

1. Holzer M. Targeted temperature management for comatose survivors of cardiac arrest. N Engl J Med. 2010;363(13):1256-64.

2. Lemiale $\mathrm{V}$, Dumas $\mathrm{F}$, Mongardon $\mathrm{N}$, et al. Intensive care unit mortality after cardiac arrest: the relative contribution of shock and brain injury in a large cohort. Intensive Care Med. 2013;39(11):1972-80.

3. Andreja S, Andrej M, Martin M, et al. Independent predictors of 6-month mortality in patients successfully resuscitated for out-of-hospital cardiac arrest: observational retrospective single center study. Biomed Res Int. 2018; 2018:1-7.

4. Benson DW, Williams GR, Spencer FC, et al. The use of hypothermia after cardiac arrest. Anesth Analg. 1959;38(6):423-8.

5. Williams gr Jr, spencer Fc. the clinical use of hypothermia following cardiac arrest. ann surg 1958;148:462-8.

6. Ravitch MM, Lane R, Safar P, et al. Lightning stroke. Report of a case with recovery after cardiac massage and prolonged artificial respiration. N Engl J Med. 1961;264:36-8.

7. Bernard S. Treatment of comatose survivors of out-of-hospital cardiac arrest induced hypothermia. N Engl J Med. 2002;346(8):557-63.

8. Hypothermia after Cardiac Arrest Study Group. Mild therapeutic hypothermia to improve the neurologic outcome after cardiac arrest. N. Engl. J. Med. 2002;346:549-56.

9. Hachimi-Idrissi $\mathrm{S}$, Corne L, Ebinger $\mathrm{G}$, et al. Mild hypothermia induced by a helmet device: a clinical feasibility study. Resuscitation. 2001;51:275-81.

10. Monsieurs KG, Nolan JP, Bossaert LL, et al. European resuscitation council guidelines for resuscitation 2015: section 1. Executive summary. Resuscitation. 2015;95:1-80.

11. Callaway CW, Donnino MW, Fink EL, et al. Part 8: post-cardiac arrest care: 2015 American Heart Association Guidelines update for cardiopulmonary resuscitation and emergency cardiovascular care. Circulation. 2015;132: S465-82.

12. Deakin CD, Nolan JP, Soar J, et al. European resuscitation council guidelines for resuscitation 2010 section 4. Adult Advanced Life Support Resuscitation. 2010:81:1305-52.

13. Howes D, Gray SH, Brooks SC, et al. Canadian Guidelines for the use of targeted temperature management (therapeutic hypothermia) after cardiac arrest: A joint statement from The Canadian Critical Care Society (CCCS), Canadian Neurocritical Care Society (CNCCS), and the Canadian Critical Care Trials Group (CCCTG). Resuscitation. 2016;98:48-63.

14. Stanger D, Mihajlovic $V$, Singer J, et al. Effects of targeted temperature management on mortality and neurological outcome: a systematic review and meta-analysis. Eur Heart J Acute Cardiovasc Care. 2018;7(5):467-77.

15. Tommasi $E$, Lazzeri $C$, Bernardo $P$, et al. Cooling techniques in mild hypothermia after cardiac arrest.[J]. J Cardiovasc Med (Hagerstown). 2017;18:459-66.

16. Vaity C, Al-Subaie N, Cecconi M. Cooling techniques for targeted temperature management post-cardiac arrest. Crit Care. 2015;19:103.

17. Keller E, Imhof HG, Gasser S, et al. Endovascular cooling with heat exchange catheters: a new method to induce and maintain hypothermia. Intensive Care Med. 2003:29:939-43.

18. Al-Senani FM, Graffagnino C, Grotta JC, et al. A prospective, multicenter pilot study to evaluate the feasibility and safety of using the CoolGard system and icy catheter following cardiac arrest. Resuscitation. 2004;62:143-50.

19. Holzer M, Marcus M, Sterz F, et al. Efficacy and safety of endovascular cooling after cardiac arrest: cohort study and Bayesian approach. Stroke. 2006:37:1792-7

20. Alkadri ME, Peters MN, Katz MJ, et al. State-of-the-art paper: Therapeutic hypothermia in out of hospital cardiac arrest survivors. Catheter Cardiovasc Interv. 2013;82:E482-90.

21. JPT H, Green S. Cochrane handbook for systematic reviews of interventions. Version 5.1.0 [updated Mar 2011]. London: The Cochrane Collaboration. http://handbook.cochrane.org

22. Flemming $\mathrm{K}$, Simonis $\mathrm{G}$, Ziegs $\mathrm{E}_{\text {, et }}$ al. Comparison of external and intravascular cooling to induce hypothermia in patients after CPR. Ger Med Sci. 2006:4:Doc04.

23. Arrich J, European Resuscitation Council Hypothermia After Cardiac Arrest Registry Study Group. Clinical application of mild therapeutic hypothermia after cardiac arrest. Crit Care Med. 2007;35:1041-7. 
24. Flint AC, Hemphill JC, Bonovich DC. Therapeutic hypothermia after cardiac arrest: performance characteristics and safety of surface cooling with or without endovascular cooling. Neurocrit Care. 2007;7:109-18.

25. Fink $\mathrm{K}$, Schwab T, Bode $\mathrm{C}$, et al. Endovascular or surface cooling?: therapeutic hypothermia after cardiac arrest. Anaesthesist. 2008;57:1155-60.

26. Ferreira I, Schutte M, Oosterloo E, et al. Therapeutic mild hypothermia improves outcome after out-of-hospital cardiac arrest. Neth Heart J. 2009;17: 378-84.

27. Gillies MA, Pratt R, Whiteley C, et al. Therapeutic hypothermia after cardiac arrest: a retrospective comparison of surface and endovascular cooling techniques. Resuscitation. 2010;81:1117-22.

28. Caulfield AF, Rachabattula S, Eyngorn I, et al. A comparison of cooling techniques to treat cardiac arrest patients with hypothermia. Stroke Res Treat. 2011;2011:690506.

29. Knapik P, Rychlik W, Siedy J, et al. Comparison of intravascular and conventional hypothermia after cardiac arrest. Kardiol Pol. 2011;69:1157-63.

30. Tømte $\varnothing$, Drægni T, Mangschau A, et al. A comparison of intravascular and surface cooling techniques in comatose cardiac arrest survivors. Crit Care Med. 2011:39:443-9.

31. Waard MCD, Banwarie RP, Jewbali LSD, et al. Intravascular versus surface cooling speed and stability after cardiopulmonary resuscitation. Emerg Med J. 2015;32:775-80.

32. Forkmann M, Kolschmann S, Holzhauser L, et al. Target temperature management of 33 degrees $C$ exerts beneficial haemodynamic effects after out-of-hospital cardiac arrest. Acta Cardiol. 2015;70:451-9.

33. Oh SH, Oh J, Kim YM, et al. An observational study of surface versus endovascular cooling techniques in cardiac arrest patients: a propensitymatched analysis [J]. Crit Care. 2015;19(1):1-12.

34. Rosman J, Hentzien M, Dramé $M$, et al. A comparison between intravascular and traditional cooling for inducing and maintaining temperature control in patients following cardiac arrest. Anaesth Crit Care Pain Med. 2018;37:129-34.

35. Kim KH, Shin SD, Song KJ, et al. Cooling methods of targeted temperature management and neurological recovery after out-of-hospital cardiac arrest: A nationwide multicenter multi-level analysis. Resuscitation. 2018;125:56-65.

36. Sonder $\mathrm{P}$, Janssens $\mathrm{GN}$, Beishuizen $\mathrm{A}$, et al. Efficacy of different cooling technologies for therapeutic temperature management: a prospective intervention study. Resuscitation. 2018:124:14-20.

37. De Fazio C, Skrifvars MB, Søreide E, et al. Intravascular versus surface cooling for targeted temperature management after out-of-hospital cardiac arrest: an analysis of the TTH48 trial. Crit Care. 2019;23:61.

38. Hoedemaekers CW, Ezzahti M, Gerritsen A, et al. Comparison of cooling methods to induce and maintain normo- and hypothermia in intensive care unit patients: a prospective intervention study. Crit Care. 2007;11:R91.

39. Pittl U, Schratter A, Desch S, et al. Invasive versus non-invasive cooling after in- and out-of-hospital cardiac arrest: a randomized trial. Clin Res Cardiol. 2013;102:607-14.

40. Deye N, Cariou A, Girardie P, et al. Endovascular versus external targeted temperature management for patients with out-of-hospital cardiac arrest CLINICAL PERSPECTIVE. Circulation. 2015;132(3):182-93.

41. Look X, Li H, Ng M, et al. Randomized controlled trial of internal and external targeted temperature management methods in post- cardiac arrest patients. Am J Emerg Med. 2018;36:66-72.

42. Review Manager (RevMan) [computer program]. Version 5.3. Copenhagen: The Nordic Cochrane Centre, The Cochrane Collaboration; 2014

43. van Swieten JC, Koudstaal PJ, Visser MC, et al. Interobserver agreement for the assessment of handicap in stroke patients. Stroke. 1988;19:604-7.

44. Brain Resuscitation Clinical Trial I Study Group. A randomized clinical study of cardiopulmonary-cerebral resuscitation: design, methods, and patient characteristics. Am J Emerg Med. 1986;4:72-86.

45. Geocadin RG, Carhuapoma JR. Medivance Arctic sun temperature management system.[J]. Neurocrit Care. 2005:3:63-7.

46. Wan X, Wang W, Liu J, et al. Estimating the sample mean and standard deviation from the sample size, median, range and/or interquartile range. BMC Med Res Methodol. 2014;14:135.

47. Higgins JPT,Green S. (2011) Cochrane handbook for systematic reviews of interventions. Version 5.1.0. The Cochrane collaboration.

48. Peberdy MA, Callaway CW, Neumar RW, et al. Part 9: post-cardiac arrest care: 2010 American Heart Association Guidelines for cardiopulmonary resuscitation and emergency cardiovascular care. Circulation. 2010;122: S768-86.
49. Glover GW, Thomas RM, Vamvakas G, et al. Intravascular versus surface cooling for targeted temperature management after out-of-hospital cardiac arrest - an analysis of the TTM trial data. Crit Care. 2016;20:381.

\section{Publisher's Note}

Springer Nature remains neutral with regard to jurisdictional claims in published maps and institutional affiliations.
Ready to submit your research? Choose BMC and benefit from:

- fast, convenient online submission

- thorough peer review by experienced researchers in your field

- rapid publication on acceptance

- support for research data, including large and complex data types

- gold Open Access which fosters wider collaboration and increased citations

- maximum visibility for your research: over $100 \mathrm{M}$ website views per year

At $\mathrm{BMC}$, research is always in progress.

Learn more biomedcentral.com/submissions 